Portland State University

PDXScholar

4-28-1995

\title{
An Analysis of Socioeconomic Effects on Scrap Paper Recycling Participation
}

Sara Phyllis Zimmerman

Portland State University

Follow this and additional works at: https://pdxscholar.library.pdx.edu/open_access_etds

Part of the Geography Commons

Let us know how access to this document benefits you.

\section{Recommended Citation}

Zimmerman, Sara Phyllis, "An Analysis of Socioeconomic Effects on Scrap Paper Recycling Participation" (1995). Dissertations and Theses. Paper 5058.

https://doi.org/10.15760/etd.6934

This Thesis is brought to you for free and open access. It has been accepted for inclusion in Dissertations and Theses by an authorized administrator of PDXScholar. Please contact us if we can make this document more accessible: pdxscholar@pdx.edu. 


\section{THESIS APPROVAL}

The abstract and thesis of Sara Phyllis Zimmerman for the Master of Science in Geography were presented April 28, 1995, and accepted by the thesis committee and the department.

COMMITTEE APPROVALS:
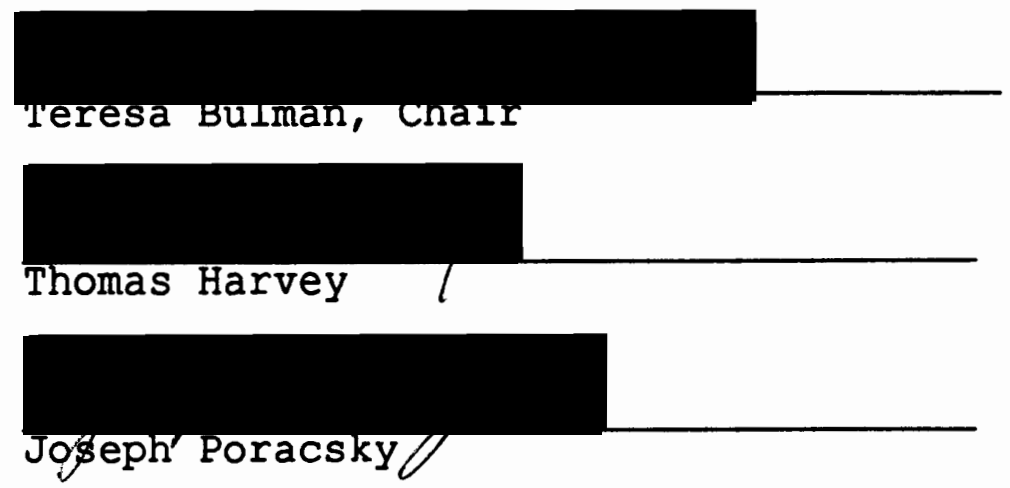

DEPARTMENT APPROVAL:

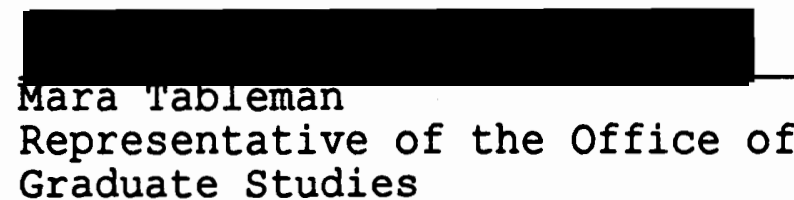

Graduate studies

Martha Works, Chair

Department of Geography

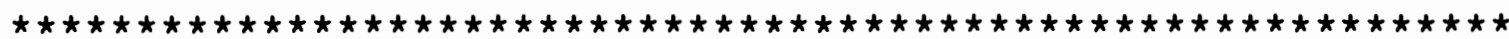

ACCEPTED FOR PORTLAND STATE UNIVERSITY BY THE LIBRARY by on 252 Tequen 1995 
AN ABSTRACT OF THE THESIS OF Sara Phyllis Zimmerman for the Master of Science in Geography presented April 28, 1995.

Title: An Analysis of Socioeconomic Effects on Scrap Paper Recycling Participation

In the Portland, Oregon, metropolitan region, almost $16 \%$ of the paper products discarded are recoverable mixedgrade scrap paper. By targeting recycling campaigns at people who tend not to recycle, participation and recovery rates may be raised. This study attempts to determine if households with greater income and education levels tend to participate in scrap paper recycling more than those with lower levels. Ten areas in Portland, each with 125 households were selected as the sample to represent the population of Portland. Data was collected about each household's recycling participation rates and socioeconomic characteristics. Statistical tests found that people who participated in scrap paper recycling had significantly different income and education levels than those who did not participate. A logistic regression model determined that scrap paper recycling participation can be predicted by knowing a person's income and education, and that the probability of participating is increased with higher income 
and higher education. Recommendations are proposed for increasing recycling participation in Portland, and elsewhere. 
AN ANALYSIS OF SOCIOECONOMIC EFFECTS ON SCRAP PAPER RECYCLING PARTICIPATION

by

SARA PHYLLIS ZIMMERMAN

A thesis submitted in partial fulfillment of the requirements for the degree of

\author{
MASTER OF SCIENCE \\ in \\ GEOGRAPHY
}

Portland State University

1995 


\section{ACKNOWLEDGEMENTS}

The greatest appreciation is extended to all who contributed valuable time to assist with this project. In particular, Barry Messer, from the Recycling Education Project at Portland State University, who recommended study ideas and provided integral information; Bruce Walker, from the City of Portland, who granted many interviews and was always willing to answer questions; Steve Apotheker, from Resource Recycling, who invited me to use the office library and spent time discussing current recycling issues; Deborah Adams, from Metro, who furnished me with essential data; and Wess Brenner, from the Academic Computing Center, who contributed substantial time to help in the analysis of the data. Additionally, Mara Tableman, from the Mathematical Sciences Department and Dr. Robert Fountain, from the Statistics Consulting Laboratory provided considerable advise about statistical procedures.

I also deeply thank my parents, Rob Allerman, Jennifer Wheelan, and other friends and family who supported me throughout the completion of this document. Joel Freedman particularly, provided continual encouragement, unending patience and sound counsel. From the Geography department, I extend my sincere gratitude to Carolyn Perry and my 
committee, Joseph Porascky, Thomas Harvey and most importantly, my advisor, Dr. Teresa Bulman. 
TABLE OF CONTENTS

PAGE

ACKNOWLEDGEMENTS $\ldots \ldots \ldots \ldots \ldots \ldots \ldots \ldots \ldots \ldots \ldots \ldots \ldots \ldots$

LIST OF TABLES $\ldots \ldots \ldots \ldots \ldots \ldots \ldots \ldots \ldots \ldots \ldots \ldots \ldots \ldots$

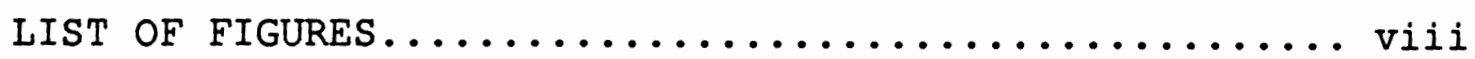

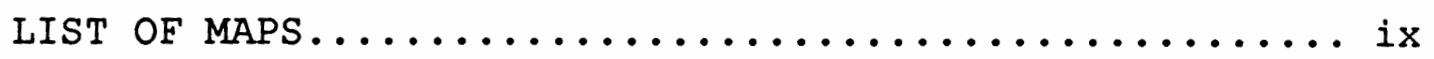

CHAPTER

I INTRODUCTION..................... I

II IITERATURE REVIEW................. 10

Paper in the Waste Stream.......... 10

Socioeconomic Factors and Their

Relationships to Recycling Rates...... 13

III STUDY AREA.................... 22

IV METHODOLOGY................... 32

Data Collection................. 32

Data Analysis................. 40

Data Limitations and Assumptions...... 43

Results of Data Analysis........... 47

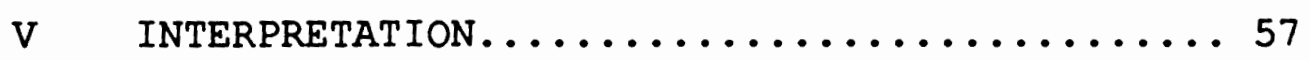

DISCUSSION................... 59

Effect of Education on Scrap Paper

Recycling Participation

Effect of Income on Scrap Paper

Recycling Participation 
THE FUTURE OF SCRAP PAPER RECOVERY IN

THE UNITED STATES............... 68

Legislation

Recovery and Utilization of Scrap Paper

Recovery Rates vs. Waste Diversion

Rates

Recommendations

REFERENCES.............................. 80

APPENDICES

A DEFINITIONS OF TERMS IN SOLID WASTE MANAGEMENT

AND RECYCLING................... 87

B PRELIMINARY RESULTS OF METRO'S 1993-1994 WASTE CHARACTERIZATION STUDY............... 89

C RECYCLE IT AT THE CURB!.............. 91

D GARGAN SURVEY QUESTIONNAIRE OF RESIDENTIAL

WASTE DISPOSAL AND RECYCIING IN PORTIAND,

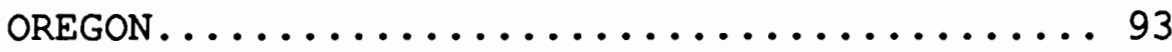

E REFUSE AND RECYCLING WEIGHT LOG SHEETS FOR

SINGLE-FAMILY CONTAINER WEIGHT STUDY IN

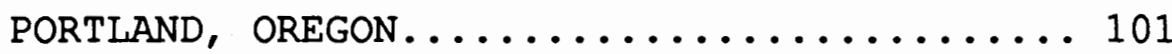

F USES FOR MIXED-GRADE SCRAP PAPER......... 106 


\section{LIST OF TABLES}

TABLE

PAGE

I Paper and Paper Products Generated in the

1993 U.S. Municipal Waste Stream........ 12

II Categories of Income and Housing Density from

which Sample Households were Selected.... 34

II Two Sample T-Test Results of Socioeconomic

Variables Comparing Scrap Paper Recycling

Participators and Nonparticipators in

Portland, Oregon..................47

IV Mann-Whitney Statistical Results of Education

Variables and Scrap Paper Recycling

Participation in Portland, Oregon....... 50

V Pearson's Chi-Square and Phi Statistical Results

of Home Ownership, Gender and Scrap Paper

Recycling Participation in Portland,

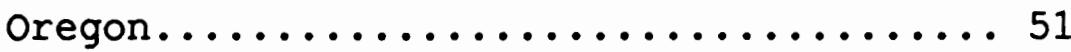

VI Results of Logistic Regression Testing Socio-

economic Factors and Scrap Paper Recycling

Participation in Portland, Oregon....... 55 


\section{IIST OF FIGURES}

FIGURES

PAGE

1. Residential Recycling Participation Rates in

Portland, Oregon.

2. Pounds of Recyclable Material Diverted From

Iandfill Disposal Per Customer Household

Per Year in Portland, Oregon (excluding

yard debris) ..................... 28

3. Estimated Pounds of Scrap Paper Diverted Per

Household Per Month in Portland, Oregon.. 30 


\section{LIST OF MAPS}

MAP

1. Portland and the Portland Metropolitan Region.

2. Waste Processing and Disposal Sites in the Portland Metropolitan Region.

3. Survey Neighborhoods in the Portland Single-Family Container Weight Study.

4. 1990 Percent of Population Age 25t in Portland, Oregon Neighborhoods Without a College Degree.

5. Median Household Income of Portland, Oregon Neighborhoods in 1990.

6. Neighborhoods in Portland, Oregon Which would Tend Not to Recycle Scrap Paper Because of Both Low Median Income and Low Education Levels 
CHAPTER I

\section{INTRODUCTION}

According to the Environmental Protection Agency (EPA), mixed-grade scrap paper (junk mail, posters, fliers, envelopes, bond paper, cereal boxes, etc.) accounts for $28 \%$ of all residential waste generated in the United States (Rogoff et al. 1992). In the Portland, Oregon, metropolitan region, approximately 24.68 of the waste delivered to landfills is paper and paperboard products. Almost 168 of the paper products discarded are recoverable mixed-grade scrap paper (Metro 1994). Shrinking landfill space, growing costs of waste disposal, and escalated costs of virgin wood should encourage society to use paper resources wisely (Haymes 1989). However, population growth, increased consumption and increased packaging are all factors which have contributed to a rise in scrap paper generation (Platt et al. 1991). By reusing and recycling paper, resources are conserved and waste is reduced at the source. Treating scrap paper as a valued resource creates a supply which can be sold for recycling. This prevents waste from entering landfills and uses the paper resource to its maximum capacity. 
Analyses of recycling programs in the United States have shown variability in recycling rates (Glenn 1992; Riley 1992) and have identified many factors that determine recycling rates (Ontario Recycling Update 1985; Vining and Ebreo 1990; Mellander 1991; Sudol and Zach 1991). This thesis will contribute to greater understanding of scrap paper recycling participation by examining the effect income and education have on an individual's likelihood to recycle scrap paper. When trying to increase recycling participation by targeting recycling efforts towards certain populations, it is helpful to know the socioeconomic characteristics of the population. Because scrap paper has been collected curbside in Portland only since september 1993, it is also important to evaluate initial program effectiveness. If curbside scrap paper recycling does not reduce sufficient waste to make collection cost effective, the recycling program may be terminated.

Since this study focuses on a single type of recyclable material, the information discovered will be of use to others examining scrap paper recycling. Determining those most likely not to participate in scrap paper recycling is an important step to increase recycling participation in the future. Presumably, resource managers will be able to apply this Portland-based research to 
increase scrap paper recycling in other municipalities as well.

The hypothesis of this thesis is that households participating in scrap paper recycling will have greater income and education levels than households that do not participate. Though many studies have shown a connection between general recycling participation, income and education (Cohen 1978; Jacobs et al. 1984; McGuire 1984; Sudol and Zach 1991; Bagby et al. 1992; Everett and Peirce 1992; Katzev et al. 1993), none have specifically examined scrap paper recycling participation.

This thesis attempts to connect income and education levels to the likelihood of recycling scrap paper. The underlying assumption is that since socioeconomic factors have been found to affect general recycling participation, these same factors will affect scrap paper recycling as well. Recycling studies often group recycling of numerous materials into a single study (Bagby et al. 1992; Everett and Peirce 1992). However, it is assumed that people who believe recycling one type of material is worthwhile generally feel recycling other materials are worthwhile as well. Recycling of scrap paper does not require beliefs different from those required for recycling other materials. This suggests that conclusions from this thesis about scrap paper recycling participation may be applied towards general recycling participation. 
The data analyzed in this thesis was collected in an joing project by the City of Portland (the City). rogram participation (measured by curbside setouts) and weight information was collected about garbage, recyclables and scrap paper from september 1993 through september 1994 . The City will use this data to determine if the scrap paper collection program reduces waste enough to be considered cost effective. The City will also evaluate waste generation, scrap paper generation and recycling information.

The City is mandated by the Oregon State Department of Environmental Quality to reduce waste (Metro 1989). By focusing recycling campaigns on the population segment which tends not to recycle, efforts to increase recycling can be maximized and recyclable recovery rates can be increased (De Young 1984; Burn and Oskamp 1986; Katzev and Pardini 1987; Spaccarelli et al. 1989; Wang and Katzev 1990; Everett and Peirce 1992). Targeting recycling campaigns prevents resources from being wasted on those who already participate. Education campaigns, pamphlets, neighborhood meetings and radio or television commercials are a few strategies which can be used to raise recovery rates (FOIz 1991). To increase recycling participation recycle, it is important that by targeting those who do not recycle, portland tends to recycle scrap the city discover who 
paper. However, because of other priorities and time constraints, the City is not analyzing that data in depth (Walker 1994). This thesis examines the City's socioeconomic data and scrap paper setout data to obtain an initial measure of who recycles scrap paper in Portland. Presumably, this information will later be used by the city to increase the number of recycling participators as well as the levels of participation by those who already recycle. Socioeconomic factors besides income and education will be tested to eliminate the possibility that other factors are responsible for recycling participation. There are many theories about why income is related to scrap paper recycling participation (these theories are explored in greater detail later). People with lower incomes may live in smaller homes which have less space for the storage of recyclables. Lack of space was shown in the Seattle study to discourage general recycling (Bagby et al. 1992). Additionally, people with higher incomes may place greater importance on environmental problems than those with lower incomes. Historically, people from the middle to upper-middle class have been the most involved in the environmental movement (Everett and Peirce 1992). Desire for a healthy environment may prompt them to take time to recycle and consciously try to reduce the amount of waste they create. 
Income could also relate to levels of consumption in that higher income individuals have more materials to recycle (Phillips et al. 1984; Vining and Ebreo 1990; Katzev et al. 1993). Those with higher income levels consume larger quantities of prepared foods which tend to have more packaging (Phillips et al. 1984). People with upper incomes also subscribe to more magazines and newspapers (Jacobs et al. 1984). These products generate waste paper which might influence their users to recycle. People with higher incomes are more likely to own their homes, which causes them to stay in the community longer and care more about the betterment of the community (Everett and Peirce 1992). Everett and Peirce (1992) found that community stability, measured by home ownership, correlates positively with recycling participation.

Lower income is usually accompanied by a lower education level (Everett and Peirce 1992). Therefore, education could also affect scrap paper recycling in a variety of ways. Education could affect recycling levels because of literacy rates. A lot of recycling education strategies use pamphlets or information mailed to homes (Folz 1991). Someone who is unable to read might not be able to understand the information and would therefore not be influenced to recycle.

Lack of education could also be a cause of the perception that scrap paper recycling is confusing (Messer 
1994). Detailed rules about which paper is acceptable for recycling may seem even more confusing to someone who cannot not read well. Frustration in understanding how to recycle paper could cause someone to give up on recycling entirely (Messer 1994). Additionally, since a lot of recycling education takes place in public schools (Folz 1991), someone who does not partake in a formal education would miss that opportunity to learn about recycling. Discovering if scrap paper recycling participation can be predicted by knowing income and education levels is a geographic pursuit. Natural resource management, which includes solid waste management such as scrap paper recycling, is related to the geographic theme of the interaction between nature and society (Wagner 1978; Simmons 1981; De Blij 1987; Miller Jr. 1987; Gaile and Willmott 1989; Simmons 1991; Rubenstein 1994). This interaction can be seen first hand by examining how waste is managed, and at what level of importance recycling is placed. In urban areas, recycling programs are evidence of policy makers managing natural resources. By determining who tends not to recycle, planners can target recycling campaigns at those people. These behavioral aspects of recycling, in the tradition of human geography, are explored in this study to answer the question of what factors may indicate whether people choose to recycle. 
This thesis is also geographic because it examines neighborhoods, or areas of Portland to determine if income and education relate to paper recycling. The sample is based on individual households, but the conclusions of this study could be extended to entire neighborhoods or regions with similar socioeconomic characteristics. The City could apply the findings of this thesis and work by geographic areas or neighborhoods to increase recycling participation.

Growing populations have placed increased pressure on the world's natural resources. Each day, more people depend on diminishing and increasingly degraded resources for daily necessities. Because of this, finding ways to assess, preserve, protect and manage natural resources is of great importance. Solid waste management is a policyoriented application to the geographic study of natural resource management.

Discovering environmentally sound ways to reduce and dispose of waste are important links in resource management. Everyday limited natural resources such as wood, oil and clean water are used. To insure the supply of useable natural resources for future generations, society should exercise care in using resources. By reusing and recycling, virgin natural resources are protected and the supply of resources is prolonged. Resources such as soil, water and air can also be protected and prolonged by disposing of waste properly. Awareness of 
the effect waste has on natural resources is essential for future appropriate waste management.

An examination of literature discussing relationships between human behavior and recycling provides a framework for understanding scrap paper recycling in Portland. The following chapter explores research completed about this subject. 
CHAPTER II

\section{LITERATURE REVIEW}

A review of research puts this thesis in the context of scrap paper recycling in the United States and provides the background for understanding recycling participation and socioeconomic factors. Appendix A contains a glossary of solid waste management and recycling terms to enhance understanding of these subjects.

\section{PAPER IN THE WASTE STREAM}

The United States waste stream contains a large volume of paper. Glenn (1992) reported that according to one EPA study, all grades of paper and paperboard are estimated at $37.5 \%$ by weight, or 31.98 by volume of the 196 million tons of municipal solid waste generated yearly in the United States. In 1990, that was the equivalent of 73 million tons of paper. EPA also estimated that the weight of the paper fraction of municipal solid waste will increase to 38.18 by the year 2000. Gill (1993) demonstrated the paper portion of the United States municipal waste stream in 1993 (Table I). Table I shows $15.5 \%$ of the municipal waste stream as paper fiber and $16.7 \%$ as containers and packaging. This means that the municipal waste stream is 
composed of 32.28 paper products. Davis (1992) estimates that 56 million tons of paper waste are disposed of in landfills annually.

Mixed-grade scrap paper estimates, like all recycling and disposal estimates, vary depending on the source and on the definition of paper grade. Using the figures from Table $I$, if the United States had a mixed scrap paper program such as Portland's, $21.5 \%$ of the municipal waste would be considered recoverable. A recycling program which only accepts newspapers would consider just $6.6 \%$ of the waste stream to be recoverable. Friberg (1993) stated that between 15 and 25 million tons of mixed scrap paper are generated annually in the United States. Much of this mixed scrap paper contributes to the more than 40 million tons of paper material discarded in landfills each year. Goldstein (1992) described a 1990 study completed in a Durham, North Carolina, landfill which found that $20.9 \%$ of the residential waste stream was mixed grade scrap paper.

Metro, Portland's regional government, reported that in the Portland metropolitan region, approximately $24.6 \%$ of the waste delivered to landfills is paper and paperboard products (Metro 1994). Metro also stated that 20.5\% of the waste delivered to landfills is recoverable paper fiber. Excluding newspapers and magazines, which are collected 
Table I

PAPER AND PAPER PRODUCTS GENERATED IN THE 1993 U.S. MUNICIPAL WASTE STREAM

\begin{tabular}{|c|c|c|c|}
\hline & $\frac{\text { Million }}{\text { Tons }}$ & $\frac{\text { Percent }}{\text { Paper }}$ & $\frac{\text { Percent }}{\text { stream }}$ \\
\hline \multicolumn{4}{|l|}{ Nondurables } \\
\hline Newspapers & 12.9 & 20.5 & 6.6 \\
\hline Office papers & 6.4 & 10.2 & 3.3 \\
\hline $\begin{array}{c}\text { Other commercial } \\
\text { printing }\end{array}$ & 5.5 & 8.7 & 2.8 \\
\hline Third-class mail & 3.8 & 6.0 & 2.0 \\
\hline $\begin{array}{c}\text { Other nonpackaging } \\
\text { paper }\end{array}$ & 3.8 & 6.0 & 1.9 \\
\hline Tissue and towels & 3.2 & 5.1 & 1.6 \\
\hline Magazines & 2.8 & 4.5 & 1.4 \\
\hline Disposable diapers & 2.6 & 4.1 & 1.4 \\
\hline Books & 1.0 & 1.6 & 0.5 \\
\hline Paper plates and cups & 0.7 & 1.1 & 0.3 \\
\hline Telephone books & 0.5 & 0.8 & 0.3 \\
\hline Total paper & 30.0 & 48.2 & 15.5 \\
\hline \multicolumn{4}{|l|}{ Containers/Packaging } \\
\hline Corrugated boxes & 23.9 & 38.0 & 12.2 \\
\hline Folding cartons & 4.3 & 6.8 & 2.2 \\
\hline Bags and sacks & 2.4 & 3.8 & 1.2 \\
\hline Other paper packaging & 1.0 & 1.6 & 0.5 \\
\hline Milk cartons & 0.5 & 0.8 & 0.3 \\
\hline Other paperboard & 0.3 & 0.5 & 0.1 \\
\hline Wrapping paper & 0.1 & 0.2 & 0.1 \\
\hline Total paper packaging & 32.6 & 51.8 & 16.7 \\
\hline MSW $=\begin{array}{c}\text { Municipal solid } \\
\text { waste }\end{array}$ & & & \\
\hline
\end{tabular}

Source: Gill 1993:59. 
separately, $15.8 \%$ of the paper discarded is recoverable mixed-grade scrap paper.

\section{SOCIOECONOMIC FACTORS AND THEIR RELATIONSHIPS TO RECYCLING RATES}

There are many demographic factors to consider when trying to determine why people recycle. Income, education, home ownership, home value, housing density, age, and gender are some of the factors analyzed to discover trends in recycling. Income and education, because they indicate both economic and social factors, have been used as general measures of socioeconomic status when researching waste and recycling trends (Jacobs et al. 1984; McGuire 1984; Phillips et al. 1984; Spaccarelli et al. 1989; Vining and Ebreo 1990; Sudol and Zach 1991; Rogoff et al. 1992; Everett and Peirce 1992; Katzev et al. 1993).

A large body of behavioral research examines the effect attitudes and beliefs have on recycling participation (De Young 1984; Vining and Ebreo 1990; Goldenhar and Connell 1993b; Katzev et al. 1993; Katzev and Wang 1994). Though an individual's attitudes, consumptive habits, or level of attention paid to world issues may be tied indirectly to income and education, this thesis focuses on socioeconomic values of income and education because they are measurable. A review of research 
examining the role demographics plays in recycling provides a background to this subject.

Many studies have found correlations between recycling rates and income levels. McGuire (1984) cited Peters who found that in 1973, the higher the income and education levels, the greater the likelihood of participation in recycling programs. McGuire also listed studies from Staten Island, New York, Tucson, Arizona, and Seattle, Washington, which confirmed this finding. Cohen (1978) looked at 218 cities' recycling program participation rates. He found that cities with higher mean income levels had greater recycling participation than those with lower mean income levels.

A study by Sudol and Zach in 1991 explored how Newark, New Jersey's recycling participation rates correlated to median income and owner occupancy. They conducted drive-by surveys on the mornings of recyclable and garbage pick-up to determine participation rates. Households which separated recyclables from garbage and set them at the curb at least one day during the month-long study period were considered to have participated. Though no specifics about the strength of the correlation were presented, income and owner occupancy data taken from census statistics were both found to be positively correlated to recycling participation (Sudol and Zach 1991). 
Vining and Ebreo (1990), found recyclers and nonrecyclers to have only statistically weak differences in terms of occupation, size and composition of household, and most categories of income. They found that recyclers tended to be older than nonrecyclers. There also tended to be differences in the ways in which people of different income and education levels received their information about recycling. Individuals with higher incomes and more education tended to receive their information from newspapers while those with lower incomes and less education received information from school programs and television. Because of these differences, one conclusion the authors came to is that tailoring recycling appeals to the demographic characteristics of target audiences is a sensible way to increase participation.

Katzev et al. (1993) also found a positive relationship between recycling participation and both income and education levels. Though their study focused on multi-family housing, the variables they tested were associated with individual participation. Neither age nor the number of individuals residing in a household were found to be significantly correlated to participation levels. However, Mellander (1991) reported that in Victoria, British Columbia, age was determined to be a factor in recycling participation. Weekly recycling 
setouts were highest among 19-24 year-olds, next highest among 25-44 year-olds, and lowest among those 65 and older.

Ontario Recycling Update (1985) reported on a study by Publishers Paper Company designed to help government agencies and recycling program operators determine who tends to recycle. They found that people tending to recycle most were over 35 years old, lived in single family housing in an area for three years or more, and had incomes of $\$ 25,000$ or more. They also found that the least likely to recycle, the most likely to be uninformed about methods of recycling and the most likely to be influenced by promotion to recycle in the future were adults between the ages of 18 and 34 who lived in apartments and had lived in the area for three years or less (Ontario Recycling Update 1985)

In 1990, the City of Seattle completed a survey which identified socioeconomic characteristics of people who participated in curbside recycling. Households which participated tended to use the smallest waste disposal containers offered by the City of Seattle, have college degrees, annual household incomes above $\$ 30,000$, and four or more people in the household. They also found that people who had knowledge about how to recycle were more likely to recycle than people who just had positive attitudes about recycling. Customers who did not participate in curbside recycling tended to live in a one 
or two person household, had not attended college, and earned less than $\$ 30,000$ annually. They said they did not recycle because they produced too few recyclables, had inadequate storage space, or worried about attracting pests (Bagby et al. 1992).

Jacobs et al. (1984) studied Leon County, Florida, single-family homes to see if a relationship existed between recycling participation and housing values. They found consistently higher levels of weekly participation in the neighborhoods with proportionately higher housing values.

Some studies have found that recycling participation relates more to neighborhood stability than socioeconomic level. Everett and Peirce (1992) found that in areas without block leaders (neighborhood volunteers who advertise and promote recycling), socioeconomic level was correlated with recycling participation. The presence of block leaders was assumed to indicate greater concern for the community and thus, greater neighborhood stability. Weigel (1977), however, found that after personal contact to promote recycling, individual levels of formal education, occupation, and levels of concern for the environment all positively correlated to the likelihood of recycling.

Everett and Peirce (1992) also looked at home ownership as an indicator of block stability. 
Neighborhoods with a majority of owner occupied homes tend to be more stable than neighborhoods composed mainly of renters. Home ownership may be used as an indicator of socioeconomic status since people with greater income levels usually own their own homes. Everett and Peirce $(1992,73)$ found home ownership 'moderately highly correlated with income and education,' though not nearly as high as income and education correlated to each other. They also found that social ties, or a sense of community correlates more highly to recycling levels than home ownership. Therefore, though home ownership can indicate block stability, ties to the community are a stronger measure of stability and a stronger predictor of recycling levels.

Everett and Peirce (1992) also found that low income blocks are more likely to have low recycling participation rates, medium income blocks are more likely to have medium participation rates, and high income blocks are more likely to have high participation rates. They found the same pattern when comparing education and home ownership rates to recycling participation rates.

Some surveys have analyzed housing density as an indicator of recycling levels and waste production. In the Victoria, British Columbia region, Mellander (1991) reported on a survey which found that individuals living in large apartment complexes (20 or more units) were less 
likely to recycle than those living in other households. Brachman et al. (1993) found that in Milwaukee, Wisconsin, multi-family units produced more waste per person with a higher percentage of recyclables, while single-family households generated considerably more waste per unit. Recycling behaviors identified in these studies may be related to the space needed for the storage of recyclables (Bagby et al. 1992). Relation of the amount of waste and recyclables produced to actual recycling levels is an area which needs further research.

Gruder-Adams (1990) examined rural versus subdivision recycling activity in Fitchburg, Wisconsin. Though participation was approximately equal in both areas, a greater amount of material by weight was recycled from subdivisions. Urban residents also set out materials more often and contributed more item types than rural residents. Gruder-Adams (1990) suggested that the peer pressure of seeing neighborhood recycling bins lining the streets might cause some urban residents to set out recyclables. Driveway length, ease of transporting bins to the curb, storage space in the house or yard, and the ability to compost were also suggested as causes of urban/rural differences.

Seasons have an effect on recycling (Jacobs et al. 1984; Rogoff et al. 1992; Anderson et al. 1993). The holiday season of high consumption can create an abundance 
of waste and recyclables. Yard debris in the summer months also loads the system with material. Volumes of seasonal yard debris vary greatly with single-family or multi-family housing types. Weather can also affect the moisture content, weight, and decomposition rate of recyclables. Extreme weather can reduce the load of recyclables by causing people to skip weeks of recyclable set-out. Brachman et al. (1993) found that in Milwaukee, Wisconsin, about 15 to $20 \%$ more waste is generated by apartments from June to september. Usually due to yard debris, singlefamily units have even greater monthly variations. September was found to be the largest quantity month while February was the lowest.

Bagby et al. (1993) stated that seasonality can affect the prices paid by the recycling industry for residential mixed paper. During the summer and early fall, mixed paper prices are often lowest. A rise in the winter and spring is usually followed by the peak of prices in April. Many irregular price movements in the mixed paper market have been caused by shifts in export demand for mixed paper. Apotheker (1993) noted that as programs mature, their success often increases. Per-ton costs of collecting recyclables are usually reduced when additional materials are collected. After Portland began collection of mixed paper, the cost of collecting recyclables fell $10 \%$ per ton. Kuniholm (1990) estimated that in early program 
development, net capture rates for individual recyclable materials may be as low as 10-20\%. As programs mature, recovery rates may reach 60-80\%. Kuniholm stated that the net capture rate for a mature multi-material program is likely to be 40-60\% of targeted materials.

The following chapter, an exploration of Portland and its recycling program, places this thesis in context with the case studies mentioned above. 
CHAPTER III

STUDY AREA

The Portland metropolitan region is situated in the northwest part of Oregon, at the confluence of the Columbia and Willamette Rivers. The metropolitan region spans Clackamas, Washington, Multnomah and Yamhill Counties (Oregon State Employment Division 1982). Map 1 shows the City of Portland boundary within the regional Metro service boundary. Map 2 shows the locations of the waste transfer and disposal sites in the Portland metropolitan region. Locations of the 10 Portland neighborhoods researched in this study are shown on Map 3.

The Portland area population is growing. As of July 1992, an estimated 1,308,700 residents, or 448 of the state's population resided in the Oregon portion of the Portland SMSA. Population grew by an estimated 23,600 people from July 1991 to July 1992. The City of Portland, with 458,275 residents, is Oregon's most populous city (Wineberg 1993). Between 1990 and 2012, population in the Portland area is predicted to increase by 505,388 , for an average annual growth rate of 1.568 . If this rate is maintained, the regional population will double by 2035 
(Oregon Department of Transportation 1993). These population growth rates have grave implications for the region's ability to handle large volumes of solid waste.

There are several agencies which regulate solid waste management in Portland, Oregon. Metro, the Portland area regional government, provides service across the boundaries of Multnomah, Clackamas and Washington counties. Metro is responsible for developing and implementing a comprehensive regional Waste Reduction Program (the Program) and disposing of waste within the Metro service district boundary. The Program is intended to substantially reduce the volume of solid waste going to landfills by source separation, post collection recycling and resource recovery. The Program also establishes a 20-year regional recycling goal. Before the oregon state Department of Environmental Quality (DEQ) will issue a permit for any landfill disposal site in Oregon, an approved program is required (Metro 1989).

In terms of solid waste disposal, Metro is responsible for rate setting, franchising, flow control and activities such as determining when a new waste reduction facility is needed (Metro 1989). Metro has also conducted surveys of recycling levels since 1986 to determine the success of waste reduction programs in the region (Metro 1992).

$\mathrm{DEQ}$ is responsible for developing legislation and administrative rules relating to waste reduction. $\mathrm{DEQ}$ also 
oversees waste reduction activities of Metro, cities and counties in the state. Additionally, DEQ monitors the 'Opportunity to Recycle Act' by reviewing wasteshed reports required of cities and counties. DEQ provides grants, loans and technical assistance to local governments. Assistance in financing recycling and resource recovery facilities are also provided by DEQ (Metro 1989).

Within the City of Portland, the Bureau of Environmental Services (BES) is in charge of collecting recyclables and solid waste to protect public health and the environment. BES also provides city residents with water quality protection, sewage treatment, waste water collection and sewer installation. The City has a policy to reduce the amount of solid waste generated and disposed by using aggressive source reduction and recycling techniques (Metro 1989).

Cities and counties in the Portland metropolitan region have responsibility for the collection of solid waste. Collection is provided by franchised private haulers with distinct service areas who are regulated by local governments (Metro 1989). In 1992, Portland joined the rest of the region in having franchised haulers (BES 1994).

In 1983, the Oregon legislature passed Senate Bill 405, the Opportunity to Recycling Act. The law stated that local governments must support the opportunity to recycle 
by providing a place for source separated materials either at the disposal site or another more convenient location. For cities with populations greater than 4,000, a minimum of monthly collection must be provided. Local governments are also required to conduct public education and recycling promotion programs (Metro 1989).

The 1991 Oregon legislature passed the Oregon Recycling Act (the Act) which set aggressive recycling goals and increased the statewide standards for recycling programs. The Act sets a $50 \%$ recovery goal for the entire state by the year 2000. By 1995, the Portland Metro area must achieve a recovery level of $40 \%$. Local governments must increase their levels of service, education and promotion. The law also defines materials, types of activities considered recycling and how disposal tonnage is to be calculated (Metro 1993a).

Following the direction of the Oregon Recycling Act, the Portland City Council set additional waste reduction and recycling goals in December 1991. These goals stated that by 1997, the amount of solid waste generated per capita should be reduced by $10 \%$ and Portland should be recycling $60 \%$ of all waste. To meet these goals, the Solid Waste and Recycling Program of BES has implemented many new recycling activities and enhanced some existing programs. For example, in 1992, the City began monthly curbside yard 
debris collection. In september 1993, the City added mixed scrap paper to recycling collection (BES 1994).

Portland's St. Johns Landfill closed in 1991 after 50 years of accepting Portland area refuse. Portland's garbage is now dumped at one of two transfer stations in the region, where it is then loaded onto semitrailer trucks and transported for final disposal approximately 150 miles east in Arlington, Oregon (BES 1990).

Costs of disposal have skyrocketed in Portland and in the nation. From 1988 to 1991, tipping fees at st. Johns Landfill went from $\$ 16.90 /$ ton to $\$ 56.85 /$ ton (BES 1990). The current tipping fee at Metro facilities is $\$ 75.00 /$ ton (Metro 1993c). Some rise in tipping fees can be attributed to the anticipated $\$ 32$ million in closure costs for the st. Johns Landfill. Funding construction and operation of new transfer stations and the Arlington Landfill have also driven tipping fees up (BES 1990).

The rise in tipping fees, the closure of the st. Johns Landfill, and the trucking of garbage to Arlington through the Columbia River Gorge have brought public attention to the topic of solid waste disposal. Demand for recycling opportunities might also be attributed to these factors (BES 1990).

Figures 1 and 2 show the residential recycling participation rates in Portland and the pounds of recyclable material diverted per customer household per 


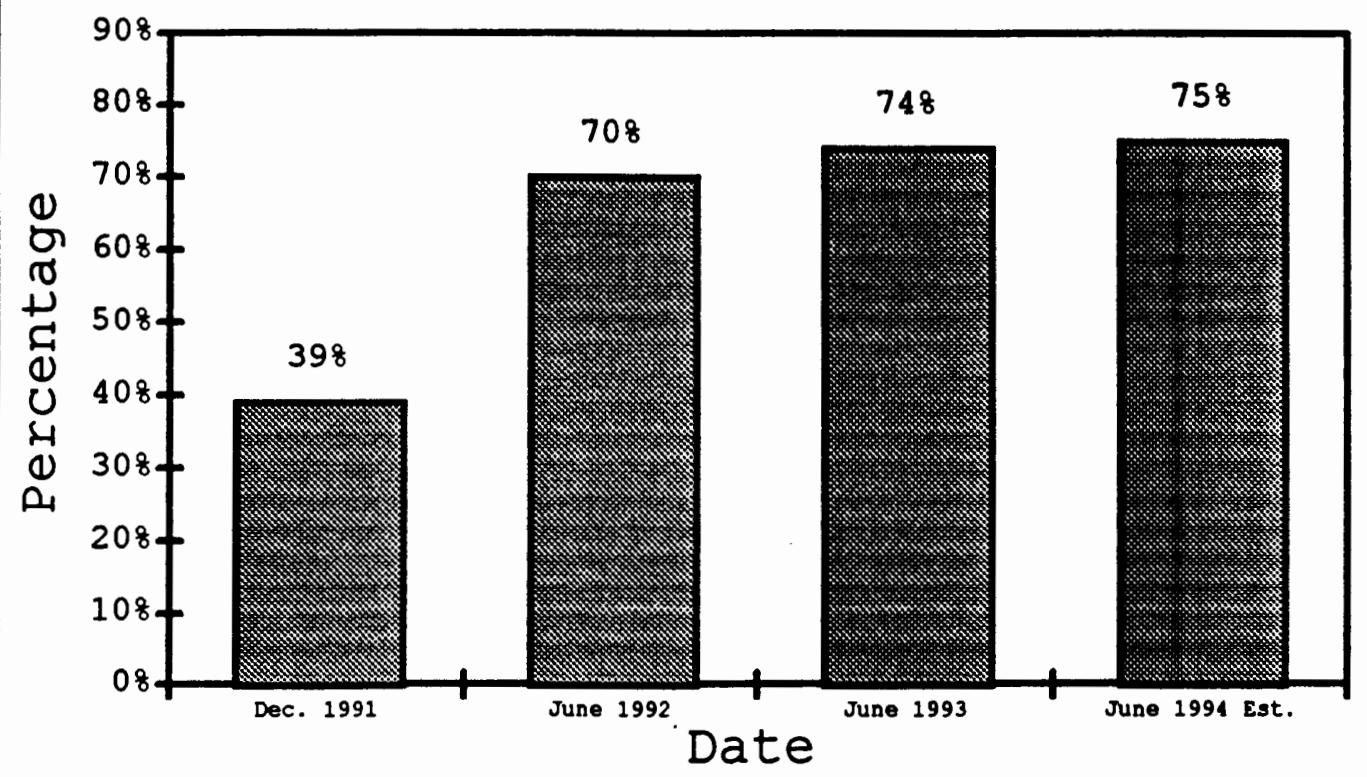

Fiqure 1. Residential recycling participation rates in Portland, Oregon. Source: Bureau of Environmental Services 1994:9.

year (not including yard debris). The residential recycling rate shown on Figure 1 includes yard debris as well as all the materials collected curbside for recycling. As people learn more about recycling and become accustomed to recycling, participation rates have risen along with the amount of material diverted from landfills. Both figures demonstrate a sharp rise in rates from 1991 to 1992 . The rise was caused by the inception of a franchised residential garbage and recycling program, and new 


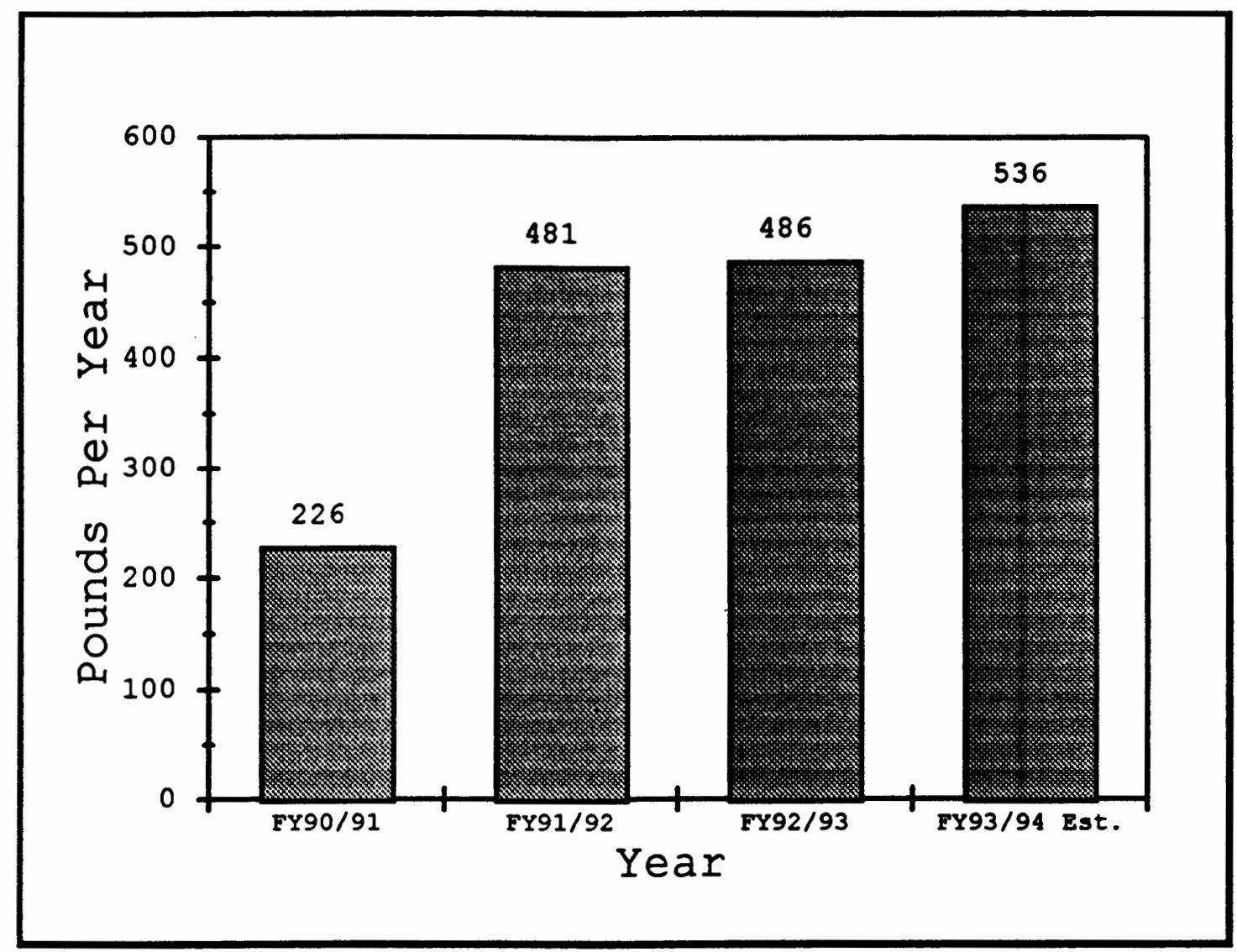

Figure 2. Pounds of recyclable material diverted from landfill disposal per customer household per year in Portland, Oregon (excluding yard debris). Source: Bureau of Environmental Services 1994:9.

recycling program elements. New aspects of the recycling program included weekly collection of recyclables on the same day as garbage collection, provision of two recycling containers, implementation of milk jug and magazine collection, and curbside yard debris collection. Because yard debris collection began in April 1992, the large volumes of material associated with collection probably 
contribute to much of the 1992 rise in recycling rates (Figure 1). Therefore, the high recycling participation rate shown on Figure 1 does not accurately demonstrate if people are participating specifically in scrap paper recycling (BES 1994).

Appendix B shows the paper portion of the waste stream composition from the preliminary results of Metro's 1993-94 Waste Characterization Study. It divides paper waste into categories and illustrates the amount of paper products that, even with available recycling, are still discarded in landfills by various generators of waste.

With regard to scrap paper alone, Figure 3 shows the estimated amount of paper diverted per household in the first four months of Portland's scrap paper collection program. Based on this data, using scrap paper recycling rates of five pounds per month, even less than November 1993 rates, 60 pounds of scrap paper per customer household could be recovered each year. In a short time, scrap paper could be the second largest material by weight diverted from residential waste (BES 1994).

Presently in Portland, recyclables are collected once a week, Monday through Friday, on the same day as garbage collection. Collection of recyclables is completed by the 'Approved Recycler,' the business entity that has received City approval of its recycling plan for its service territory. Recyclables must be set-out at the curb unless 


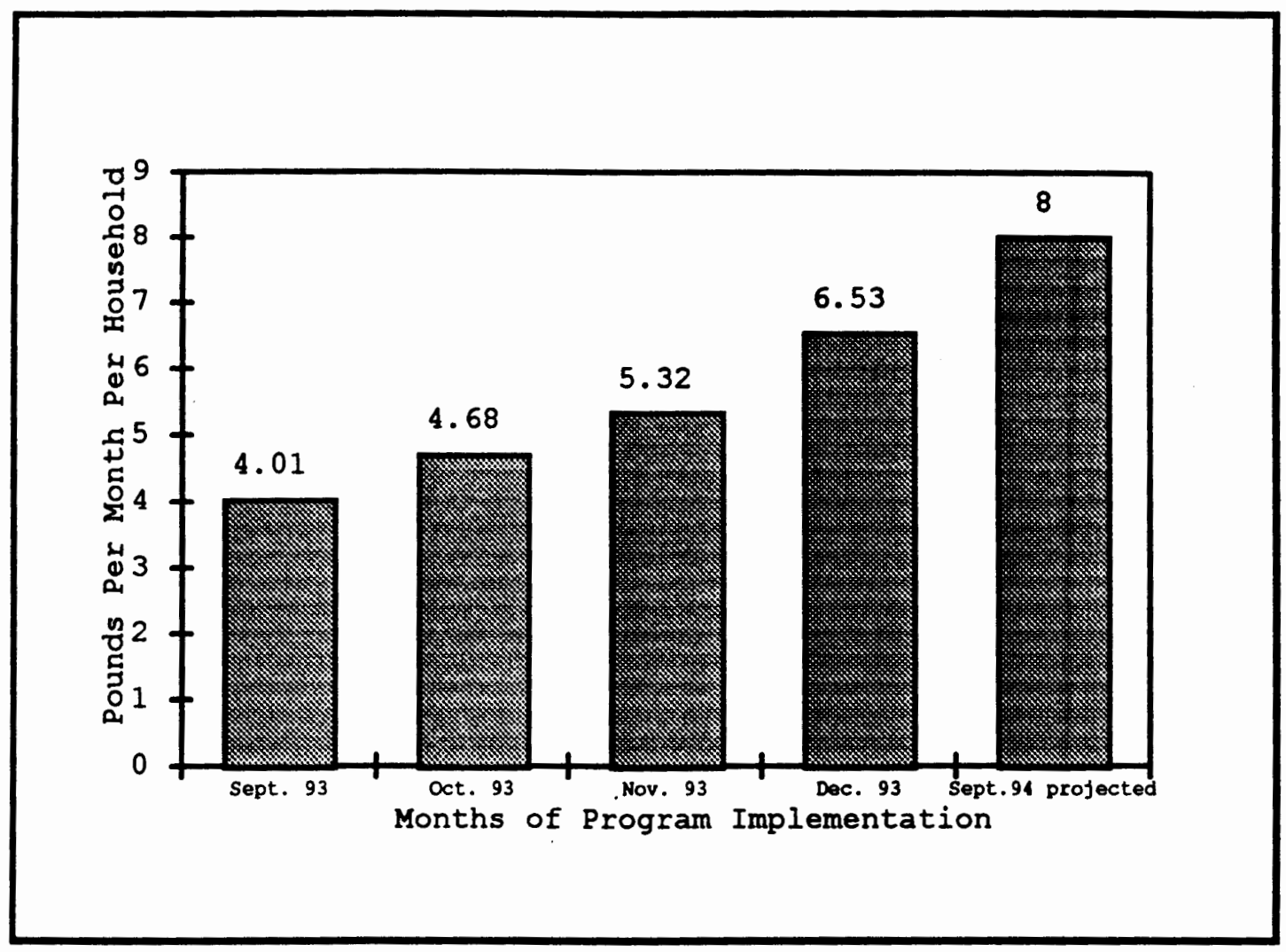

Fiqure 3. Estimated pounds of scrap paper diverted per household per month in Portland, Oregon. Source: Bureau of Environmental Services 1994b:10.

otherwise arranged. A yellow recycling bin is provided by the City and recyclables must be prepared as the City has directed in pamphlets (BES 1993). Appendix C is an example of a scrap paper recycling pamphlet available from the City.

Because recycling is already established in Portland, it is a good place to examine the changes that occur in recycling when collection of a new material such as scrap paper begins. The effects of collecting an individual 
material can be distinguished from general recycling rates when a recycling program has already been implemented. With Portland now characterized as an appropriate location for this research, the following chapter specifies the details of the study. 


\section{CHAPTER IV}

\section{METHODOLOGY}

Data collection and analysis methods used in this thesis are specified below. This information allows for duplication of results, investigation of this thesis and application towards related subjects of study.

\section{DATA COLLECTION}

The hypothesis of this thesis, that knowledge of income and education can be used to predict scrap paper recycling behavior, will be tested using standard statistical analysis. Background recycling data for this study was collected from a variety of sources including journals, publications and interviews with recycling experts at Metro, the City of Portland, and the Recycling Education Project (REP). The principal source of data was the Single-Family Container Weight Study of the Recycling Education Project. The author participated in the collection of garbage and recyclable material weight and setout information.

The City of Portland and Metro's Single-Family Container Weight Study began in September 1992. Data collection for the study was completed by REP under 
contract with Metro and the City of Portland. REP collected refuse, recycling, and yard debris weight and setout data from single-family homes for one year. The data was to be used by Metro in a forecasting model to determine regional waste generation and landfill needs. The City was to use the data for setting residential garbage service rates, determining recycling setout rates, participation rates and waste generation within Portland (Messer 1993).

The City and Metro wanted the stratified systematic sample of households to be representative of the varying income and single-family housing density levels existing throughout Portland and the metropolitan region. Though the sample selection process is described in greater detail below, the basic concept is that 19 households with certain characteristics were selected throughout the region from 19 separate garbage hauler routes or neighborhoods. Next, 125 households were selected consecutively from, and including each, of the 19 households to arrive at a sample total of 2,375 households. The sample selected the 19 households to represent Portland and the metropolitan area. However, the 125 households from each of the 19, were simply selected to mimic the criteria met by the original 19 households (Messer 1994).

To select households for use in the study, REP first looked at Census blocks and block information which showed 
median income and housing density. REP took the range of income and housing density levels from every metropolitan region block and divided them equally into segments of low, medium and high categories. This resulted in nine total categories shown on Table II.

TABLE II

CATEGORIES OF INCOME AND HOUSING DENSITY FROM WHICH SAMPLE HOUSEHOLDS WERE SELECTED

\begin{tabular}{|l|l|l|}
\hline $\begin{array}{l}\text { High Income, } \\
\text { High Housing } \\
\text { Density }\end{array}$ & $\begin{array}{l}\text { Medium Income, } \\
\text { High Housing } \\
\text { Density }\end{array}$ & $\begin{array}{l}\text { Low Income, } \\
\text { High Housing } \\
\text { Density }\end{array}$ \\
\hline $\begin{array}{l}\text { High Income, } \\
\text { Medium Housing } \\
\text { Density }\end{array}$ & $\begin{array}{l}\text { Medium Income, } \\
\text { Medium Housing } \\
\text { Density }\end{array}$ & $\begin{array}{l}\text { Low Income, } \\
\text { Medium Housing } \\
\text { Density }\end{array}$ \\
\hline $\begin{array}{l}\text { High Income, } \\
\text { Low Housing } \\
\text { Density }\end{array}$ & $\begin{array}{l}\text { Medium Income, } \\
\text { Low Housing } \\
\text { Density }\end{array}$ & $\begin{array}{l}\text { Low Income, } \\
\text { Low Housing } \\
\text { Density }\end{array}$ \\
\hline
\end{tabular}

Metro's GIS geocoding computer system used Arc Info to place all metropolitan region blocks within their corresponding nine categories (Messer 1994).

From each of the nine categories, the number of households selected was proportionate to the population of each of the three counties in Metro's service region. For instance, if one county had a population with 58 medium income levels and low housing density levels, then $5 \%$ of that county's sample was chosen with those parameters. From the nine categories, geocoding was used to first randomly select individual households which fit the 
population parameters. There were 16 households selected from 16 separate neighborhoods which represented the characteristics of the region (Messer 1994).

of the 16 households selected for the regional portion of the study, seven fell within Portland city limits. For the City to have a larger sample which represented Portland alone, three additional households were selected. This brought the total Portland sample up to ten households, one from each of ten separate neighborhoods in Portland. The three additional households were selected in much the same way as the regional sample, except that instead of having the households represent the population characteristics of the three counties, they represented the population characteristics of Portland (Messer 1994).

The total number of households for Portland's sample $(1,250)$ was chosen by REP after determining it to be a statistically valid sample size (Messer 1994). The City's economist, Jim Hagerman, agreed statistically that ten neighborhoods with 125 households in each would be an appropriate sample size to represent the population of Portland. The City also considered a study with this sample size to be economically feasible (Walker 1994). Though a larger sample size is always more desirable, this thesis used secondary data and was therefore limited to the sample determined by the City. It was necessary to assume that the developers of the can weight study were 
knowledgeable and qualified in choosing a valid, representative sample. This author was also assured by statistics experts that the sample was well within an appropriate size to represent Portland (Fountain 1995; Tableman 1995).

Including the three additional households chosen within Portland, the total sample size across the region was now 19 households from 19 neighborhoods. This number was arrived at by adding the three additional households selected for the Portland specific sample to the 16 households from the original regional sample. Container weights from the three additional households were kept separate from the 16 base households so as not to distort Metro's regional sample (Messer 1994).

After selection of 19 homes portraying the varying income and housing density levels throughout the Portland region, the consecutive 125 households from each of the 19 were selected to facilitate the operation of weighing containers. It is more efficient and convenient to weigh the containers of households along one garbage hauler route as opposed to households scattered throughout the City. It is also more efficient to maintain contact with 19 haulers instead of hundreds. For these reasons, 125 households were chosen along garbage hauler routes beginning from, and including each of the 19 households. In total, 2, 375 homes were selected throughout the Portland region from all 
income and housing density levels. The City's segment of the study contained 1,250 households, or 125 households from each of ten neighborhoods (Messer 1994).

By selecting homes along garbage routes, the assumption was made that houses along the same routes have approximately the same income and housing density levels. This, of course, is not always true. Sometimes a hauler's route travels through very diverse neighborhoods. The route may cross a road separating an older neighborhood from a new, expensive subdivision. In the few circumstances such as this, REP took the original sample house from the 19 and selected the string of 125 houses which were located consecutively in a neighborhood of the same general character. REP conducted a visual inspection to determine which households were within similar neighborhoods. REP based its judgment on apparent differences in housing density and character of the neighborhood (Adams 1994; Messer 1993).

In september 1993, a year after the regional REP study began, the City implemented its first city-wide curbside collection of mixed-grade scrap paper. Though the regional portion of the study ended, The City asked REP to continue the container-weight study for another year, through September 1994. The City will use the container-weight data to measure impacts of scrap paper collection on waste generation and recycling (Messer 1994). 
In 1993, the sample size changed slightly because one garbage hauler within the Portland sample did not want to continue participating in the study. The City's total sample size dropped from ten to nine neighborhoods with 125 households in each $(1,125$ households). Despite this reduction, the sample size is still considered statistically valid (Messer 1994; Walker 1994; Fountain 1995; Tableman 1995).

The data used in this thesis is the same scrap paper data collected by REP and the City of Portland. The City is using the data to estimate the public's knowledge of the recycling system and to determine which neighborhoods tend to use the largest garbage cans (Walker 1994). This thesis will determine whether income and education may be used as predictors of scrap paper recycling participation. Though REP and the City collected all four quarters of a year's worth of data, this thesis will only examine the three quarters of data available at this time. The data analyzed spans the fall, winter and spring quarters of September 1993 through June 1994. There was a total of six weeks of data collection, two weeks each quarter or season (walker 1994). With 1,125 households measured over six weeks, there is a possible 6,750 observations of scrap paper setouts.

Over the entire year-long study, each household's refuse and recycling containers were weighed eight times, 
two weeks in each season (i.e., fall, winter, spring, summer) by REP. Scrap paper was weighed by itself one week each season, or four times over the year. However, this thesis does not study the weights of refuse or recyclables, only recycling participation (setouts). Items present in the recycling bin were marked on a log sheet each of the eight times over the year. Scrap paper is one of the items which was noted for its presence (Messer 1994).

To determine waste disposal practices, recycling practices and opinions of the residents in the sample area, a telephone survey was conducted in May-June of 1993. The survey also included questions about income, education and other socioeconomic factors. This survey was completed by Gargan Research, a local market research company. Appendix $D$ is the questionnaire that was used in this survey.

Each week, while REP collected household refuse container-weight information, a separate log sheet was kept for each container set out at the curb. One log sheet was used for keeping track of refuse, one was for recycled material and one was for yard debris. Another sheet was available for field observation notes. Appendix E contains the refuse and recycling weight log sheets, the field observation sheet and the weight log code explanation sheet. This study focuses on the data recorded on the recycling weight $\log$ sheet. 
Data Analysis

All of the weight data, setout data and socioeconomic data was entered into spreadsheet format by REP. The author received the data from Metro in a Statistical Package of the Social Sciences (SPSS) system file with missing values already assigned as missing values. Income and education questions from the Gargan Research survey were tested statistically to determine if recycling participants and nonparticipants varied according to income and education. Other socioeconomic factors were also initially included in the model to explore the significance of their correlation to scrap paper recycling participation.

When the author received the data, Metro had created additional variables based on the survey's socioeconomic data. For instance, a categorized household education variable was created by averaging the education levels of all household residents over age 25 and putting the education levels into categorized ranges. A categorized income variable was created by separating household income into low, medium and high categories. Many other variables, such as highest education in household, were modified in this way to allow for generalizations of the sample (Adams 1994). Data about property value, acreage 
and building value were obtained by Metro from the county assessors department (Massie 1994).

Performing the difference of means $t$-test, the MannWhitney Wilcoxon Rank Sum test (the Mann-Whitney) and the chi-square and Phi tests were the first steps in data analysis. These tests are used to determine if populations of scrap paper recycling participators and nonparticipators are from significantly different populations (Blalock 1972; Lehmann 1975). On all statistical tests, a .05 level of significance was chosen to provide maximum statistical power while controlling the probability of error (Wilcox 1987; Marascuilo and Serlin 1988; Nowaczyk 1988).

The statistical tests performed were dictated by the types of data generated from each survey question. For example, some statistical tests created for ordinal level data cannot be used to test dichotomous data (Blalock 1972). Since the dependant variable was dichotomous (participation vs. non-participation) and the independent variables were interval level data, the $t$-test was used to match participation against household size (question 12 on the Gargan Survey), age of persons \#1, \#2, \#3, and \#4 (question 17), household income (question 21a), household income per person, computed income (actual or range), building value, property value and acreage.

To test ordinal variables for a difference in participators and nonparticipators, the Mann-Whitney test 
was used. The ordinal variables tested include categorized income, categorized household education, and highest educational level achieved in household.

To test dichotomous or nominal variables against nominal variables, chi-square was used to determine if a relationship existed between variables. Phi was used to determine the strength of relationship (Blalock 1972). The variables tested against participation were owning or renting the home (question 18), changes in household size (question 13), gender of persons \#1, \#2, \#3 and \#4 (question 17) and six dichotomous variables which dealt with education levels.

Frequency tables were also used with survey questions to obtain additional information about the sample as a whole. Frequency tables were conducted on questions such as interruption of garbage service (question 1), changes in household size (questions 13, 14a, 14b), and number of temporary household members (question 15).

The next step in analyzing the data was to run a hierarchical cluster analysis. Cluster analysis presents a hierarchy of the degree of relationship between variables. It searches for relatively homogeneous groups of variables, shows which variables correlate to each other and can suggest which variables to test in a regression analysis (Norusis 1990). The variables tested in the cluster analysis were: recycling participation, property value, 
building value, acreage, income categories (high, medium and low), and education categories (some high school, high school graduate, some college, college graduate, post baccalaureate). These variables were selected because they were significant when tested with the statistical tests described above. Elaboration of statistical results will appear later in this chapter.

Logistic regression analysis was the final step in data analysis. It was employed to investigate whether the socioeconomic variables can be used as predictors of scrap paper recycling participation. The model tests the significance of the probability that recycling scrap paper is related to, or predicted by the variables. Two regression analyses were completed. The first analysis eliminated variables which were not significant at the .05 level, the second was the final model.

\section{DATA LIMITATIONS AND ASSUMPTIONS}

Initial problems with the data as well as assumptions made in this study must be identified. There was cause for some concern about the size of the sample. One of the haulers withdrew from the study reducing the sample by 125 households, from 1,250 to 1,125 total households. Additionally, some cases had to be dropped from the study because of change in garbage service, refusal to respond to the survey, language barriers, or house vacancy. The final 
sample size of households having both refuse data and survey data was 952. Though the sample was reduced, it was still considered large enough to statistically represent the population of Portland (Messer 1994; Walker 1994; Fountain 1995; Tableman 1995). Sample panel attrition in these numbers can be expected when conducting any study. Statistical analysis depended on the availability of socioeconomic data. Households without this data were recorded as missing values and simply left out of the analysis. If someone refused to answer only particular questions on the survey, that household was recorded as a missing value for those questions only. Though problems like these decreased the sample size for some questions, it did not invalidate the findings (Messer 1994; Walker 1994; Fountain 1995; Tableman 1995).

Another concern was the possibility of residence change in the time between survey completion and collection of the data used in this thesis. The survey for the regional portion of the study was completed in May-June 1993, while the Portland-specific data used in this thesis was collected from September 1993-June 1994. However, only $1.4 \%$ (question 1 ) of the sample had moved within the six months previous to the survey. Even if a 4.28 change in residence occurred between the time of the survey and time of participation data collection, the sample size would 
only be reduced by 40 households, not a concern for survey validity (Fountain 1995; Tableman 1995).

This study defined participation in the scrap paper recycling program as households having at least one setout in the period of measurement. This definition was adopted because it gave the greatest leeway towards households that did not participate every week. Results showed 341 of a possible 952 households, or $35.8 \%$ of households participated in curbside scrap paper recycling. This study obtained a 1008 sample of the 952 households because nonsetouts were not considered missing data but were assumed to be households choosing not to setout scrap paper. This is a valid assumption because whether the household actually chose not to setout scrap paper, scrap paper was not recycled at that particular household on the date recorded.

Another data inconsistency occurred when scrap paper was recorded on the log sheet. Some weeks had actual weights of scrap paper recorded while other weeks had scrap paper recorded with a symbol. To correct this problem, either method of recording scrap paper setouts was considered valid. The letters ' $P$ ' and ' $X$ ' were both used as symbols for the presence of scrap paper. Upon consulting original data entry sources, it was assured that these symbols each represented scrap paper in the recycling bin (Adams 1994). To aid in statistical analysis, a new 
dichotomous variable was created in which ' 1 ' represented a setout (participation) and ' $O$ ' represented no setout (nonparticipation).

Data collection problems are issues which cannot be resolved without duplicating the entire study. Because REP had difficulties finding people willing to collect the data on a continuous basis, some observations could have been missed when workers were unfamiliar with the collection process. The rushed manner of data collection and problems coordinating with hauler pick-up might also have caused some errors. Though these problems could have affected the completeness of the sample and the assumption that all nonsetouts were intentional, they did not occur often (Messer 1994). Even with missed observations, $35.8 \%$ scrap paper recycling participation in the first three quarters of the year is a substantial accomplishment.

Another problem which cannot be compensated for is the limited amount of data used in this study. Since the curbside scrap paper collection program is only a year old, more than three quarters worth of data is not yet available. Even with the limited amount of data, the City finds this initial program evaluation to be useful (Walker 1994). 


\section{RESULTS OF DATA ANALYSIS}

Results of the statistical analysis were varied. Table III presents the t-test results for the variables relating to income. The $t$-test showed there was not a significant difference $(.086)$ in the mean household income (question 21) of those that participated in scrap paper recycling and those who did not. Although not significant,

TABLE III

TWO SAMPLE T-TEST RESULTS OF SOCIOECONOMIC VARIABLES COMPARING SCRAP PAPER RECYCLING PARTICIPATORS AND NONPARTICIPATORS IN PORTLAND, OREGON

\begin{tabular}{|c|c|c|}
\hline Variables & T Value & $\begin{array}{c}\text { 2-Tailed } \\
\text { Significance }\end{array}$ \\
\hline $\begin{array}{c}\text { Mean Household } \\
\text { Income } \\
\text { (question 21) }\end{array}$ & -1.72 & .086 \\
\hline $\begin{array}{c}\text { Computed Mean } \\
\text { Household Income }\end{array}$ & -4.58 & .000 \\
\hline $\begin{array}{c}\text { Household Income } \\
\text { Per Person } \\
\text { Property Value }\end{array}$ & -2.05 & .041 \\
\hline Building Value & -2.71 & .002 \\
\hline Acreage & -2.61 & .009 \\
\hline Number in Household & -.18 & .856 \\
\hline
\end{tabular}


the mean household income of those that participated was 12.68 higher than those who did not participate.

Conversely, a variable computed by Metro also showing household income, was significant when using the t-test $(.000)$. This variable was computed to obtain the largest sample possible for this question. Since some people did not wish to reveal their exact household income, they were instead asked to relate their household income within a range of values. Metro therefore retained the actual household income value if it was present and if only a range of income levels was offered, the midpoint of the range was used as the household income value. The computed average household income of people that recycled was 26.28 higher than people that did not recycle. The t-test showed that participation is highly significantly dependant on computed average household income.

Participation in scrap paper recycling was also shown to be significantly dependant on household income when income was recorded in a range of ten values for each household. The Mann-Whitney test demonstrated household income to be significant at the .0000 level. People who recycled had $25.1 \%$ higher ranges of income than people who did not recycle.

Metro calculated household income per person by dividing the number of people over age 25 in the household into the household income. Participation was also found to 
be significantly dependant on this variable (.041). Those who participated had $13.4 \%$ higher household income per person than those who did not.

Property value, building value and acreage are also variables which could be related to income. The 2-tailed significance values for these variables showed a significant difference between populations of participators and nonparticipators (Table III). Property value was significant at the .002 level. Scrap paper recycling participators were found to have $23.4 \%$ higher property values than nonparticpators. Building value was also significant at the .007 level, while acreage was significant at the .009 level. Those who participated had $23.0 \%$ higher building values and $14.6 \%$ more acreage of property than nonparticipators.

The t-test was also used to test size of household (question 12). Results did not show participators and nonparticipators to be from significantly different populations (Table III).

Because education variables were ordinal, the MannWhitney test was used. Both education variables showed scrap paper recycling participation to be significantly dependant on education (Table IV). The categorized household education variable was calculated by Metro. To generate this variable, Metro divided the average years of schooling for everyone over age 25 in a household into five 
education categories. The education categories were: some high school, high school graduate, some college or technical school, college graduate, and post baccalaureate.

The Mann-Whitney test determined categorized household education to be significant at the .0001 level. Those who recycled had $15.8 \%$ average higher educations by categories than those that did not recycle scrap paper. When testing the highest educational level achieved in a household, the Mann-Whitney test found a .0000 level of significance. Recyclers had, on average, $19.5 \%$ higher educations than nonrecyclers.

TABLE IV

MANN-WHITNEY STATISTICAL RESULTS OF EDUCATION VARIABLES AND SCRAP PAPER RECYCLING PARTICIPATION IN PORTLAND, OREGON

\begin{tabular}{|l|l|}
\hline Variables & 2-Tailed Probability \\
\hline $\begin{array}{l}\text { Categorized Household } \\
\text { Education }\end{array}$ & .0001 \\
\hline $\begin{array}{l}\text { Highest Educational Level } \\
\text { Achieved in Household }\end{array}$ & .0000 \\
\hline
\end{tabular}

Because the rest of the variables were either dichotomous or nominal, Pearson's chi-square statistic was used along with Phi. Pearson's chi-square tested the null hypothesis that there is no association between scrap paper recycling participation and home ownership. The same tests were used to find the association between scrap paper recycling participation and gender (Table V). 
There was found to be a significant association between scrap paper recycling participation and whether a person owns the home $(.00)$. However, the Phi value which measures the strength of the correlation between these two variables was only.16, a weak linear relationship. As Table V demonstrates, similar conclusions can be drawn about participation and gender of person \#2. The findings about gender of person \#1, person \#3 and person \#4 showed no association between participation and gender.

\section{TABLE V}

PEARSON'S CHI-SQUARE AND PHI STATISTICAL RESULTS OF HOME OWNERSHIP, GENDER AND SCRAP PAPER RECYCLING PARTICIPATION IN PORTLAND, OREGON

\begin{tabular}{||c|c|c|}
\hline Variable & $\begin{array}{c}\text { Pearson's Chi-Square } \\
\text { P-Values }\end{array}$ & Phi Value \\
\hline \hline Own or Rent Home & .00 & .16 \\
\hline $\begin{array}{c}\text { Gender of Person } \\
\# 1\end{array}$ & .67 & .03 \\
\hline $\begin{array}{c}\text { Gender of Person } \\
\# 2\end{array}$ & .05 & .09 \\
\hline $\begin{array}{c}\text { Gender of Person } \\
\text { \#3 }\end{array}$ & .53 & .05 \\
\hline $\begin{array}{c}\text { Gender of Person } \\
\# 4\end{array}$ & .30 & .07 \\
\hline
\end{tabular}

The next step in data analysis was the hierarchical cluster analysis to find degree of association between variables. Variables tested included: recycling 
participation, property value, building value, acreage, income and education.

The income variable used in the cluster analysis was household income (question 21) recorded as a range of values. This variable was chosen to achieve the greatest sample size. There were 715 households which answered this question as opposed to 373 households which offered the exact value of their household income. Since the cluster analysis does not allow nominal or ordinal data, dichotomous dummy variables were created. Income was divided into three equal segments of low $(\$ 0-\$ 19,999)$, medium $(\$ 20,000-\$ 49,999)$ and high $(\$ 50,000$ and above). Households were then recoded into the three new dummy variables. If a household fell within the income range, it was recorded as '1.' If the household was not within that range, it was recorded as ' 0 .'

The education variable used was highest education achieved in the household. There were 881 respondents to this question. This variable was chosen to represent education because it had such a high significance value when tested with the Mann-Whitney test. It was necessary to create dummy variables from this variable as well. The dummy levels of education were: some high school, high school graduate, some college or technical school, college graduate, post baccalaureate. Highest household education 
was recorded as ' 1 ' if within the category and ' 0 ' if it was not.

The hierarchical cluster analysis presented a few interesting results. High income and post baccalaureate education were highly related. Though the focus of this thesis is not the effect of acreage on scrap paper recycling participation, the cluster analysis did show acreage and some high school to be related. Though scrap paper recycling participation was not related strongly to any variable, it stayed with high income for longer than any others. Since the cluster analysis did not show any variable to be completely unrelated, all of the variables were tested in the logistic regression model. The final step in data analysis was logistic regression analysis. Logistic regression functions are used to predict the percentage chance of an individual doing something, or to describe the nature of the relationship between the dependent variable and one or more independent variables. Logistic regression analysis determines if the independent variables can be used collectively to predict whether someone will recycle.

The first try at logistic regression analysis tested all of the cluster analysis variables. Note that for each variable which had been converted to dummy variables, one less dummy variable was used in the model to assure unique estimates. Logistic regression was then executed again on 
variables with smaller p-values (higher degrees of significance). The variables with the most significant pvalues were: building value (BLDGVAL) at .1860, property value (PROPVAL) at .1903, low income (LOWINC) at .0007 and high school graduate (HSGRAD) at .1012.

The second run of the model tested the same variables but this time included college graduate (COLGRAD). The college graduate $p$-value (.2820) from the first model run was used. The second model run resulted in a smaller pvalue for college graduate (.0249) than the first model's high school graduate $(.0426)$ value. Therefore, the final model used the college graduate variable. Table VI summarizes the results of the final logistic regression model. The probability of recycling scrap paper is significantly related to, or predicted by the variables on Table VI . Individual chi-square results for each variable are also shown on Table VI. The logistic regression model's collective chi-square significance was .0000 .

The formula shown below is used to find the estimated probability of someone participating in scrap paper recycling as a function of the above socioeconomic variables:

$$
\text { prob }=P(\text { participation }=1)=[1+\exp (-Z)]^{-1}
$$

where $Z=-.8107-.000015$ (BLDGVAL) +.4102 (COLGRAD) .8219 (LOWINC) +.0000126 (PROPVAL). 
The formula turns the results of logistic regression analysis (parameter estimates from Table VI, or $\mathrm{Z}$ ) into a probability of participating in recycling (Neter et al. 1989:582).

TABLE VI

RESULTS OF LOGISTIC REGRESSION TESTING SOCIOECONOMIC FACTORS AND SCRAP PAPER RECYCLING PARTICIPATION IN PORTLAND, OREGON

\begin{tabular}{|c|c|c|c|c|}
\hline variable & $\begin{array}{c}\text { parameter } \\
\text { estimate }\end{array}$ & $\begin{array}{c}\text { Wald chi- } \\
\text { square }\end{array}$ & $\begin{array}{c}\text { p-value of } \\
\text { chi-square }\end{array}$ & $\begin{array}{c}\text { estimated } \\
\text { odds } \\
\text { ratio }\end{array}$ \\
\hline $\begin{array}{c}\text { building } \\
\text { value }\end{array}$ & $-1.5 \mathrm{E}-05$ & 3.9065 & .0481 & 1.0000 \\
\hline $\begin{array}{c}\text { property } \\
\text { value }\end{array}$ & $1.26 \mathrm{E}-05$ & 4.6996 & .0302 & 1.0000 \\
\hline low income & -.8219 & 13.0321 & .0003 & .4396 \\
\hline $\begin{array}{c}\text { college } \\
\text { graduate }\end{array}$ & .4102 & 5.0333 & .0249 & 1.5071 \\
\hline
\end{tabular}

The estimated odds ratios reported in Table VI also reveals important results. The odds of participating in scrap paper recycling are not affected or changed by building value or property value since each has an odds ratio of 1.0000 .

Low income has an odds ratio of .4396 . Since this value is less than 1 , it indicates that low income decreases an individual's odds of participating. In fact, the odds of participation are decreased by $56.04 \%$ for someone with low income. The odds that someone with medium 
or high income will participate in scrap paper recycling are 1 divided by $.4396(1 / .4396)$, or 22.74 . This means that the odds of someone with medium or high income participating is 22.74 times as great than for someone with low income.

Being a college graduate has a positive effect on a person's likelihood to recycle scrap paper. The estimated odds ratio of the college graduate variable is 1.5071 . Since this value is larger than 1 , it signifies that being a college graduate increases a person's odds of participating. Specifically, being a college graduate increases the odds of recycling by 50.718 .

A number of conclusions may be drawn about the preceding data analysis, and although some data weaknesses exist, clear trends emerged through this analysis. The following chapter provides an interpretation of these trends. 


\section{CHAPTER V}

\section{INTERPRETATION}

Despite data limitations, meaningful conclusions can be drawn regarding the hypothesis of this thesis. The hypothesis that households which participate in scrap paper recycling have greater income and education levels than households which do not participate was tested statistically and supported.

Statistical analysis of the data supported the part of the hypothesis which stated that participators in scrap paper recycling have greater educations than nonparticipators. The Mann-Whitney test demonstrated scrap paper recycling participation to be strongly dependant on education. In other words, populations of recyclers and nonrecyclers were highly significantly different. The logistic regression model showed that scrap paper recycling participation can be predicted by knowing a person's educational level. The probability of participating in scrap paper recycling is increased with higher education levels. Logistic regression also demonstrated that education has a greater impact on recycling behavior than income. 
Map 4 shows the educational levels of neighborhoods within Portland in 1990. Applying the findings in this thesis, it can be concluded that the areas with lower educational levels are likely to be the areas with low recycling participation levels.

The hypothesis segment which stated that scrap paper recyclers tend to have greater incomes than nonrecyclers, was also substantiated. Though the variable for mean household income was not significant in the t-test, that variable had an extremely small sample size. The t-test did find scrap paper recycling participation to be significantly dependant on all the other income related variables such as computed household income, property value and building value. The logistic regression model demonstrated that income can be used to predict recycling participation. Someone with higher income is more likely to recycle scrap paper than someone with lower income. Map 5 demonstrates the median household income of Portland neighborhoods in 1990. Based on the findings of this thesis, the low income neighborhoods could also be classified as the neighborhoods which would tend not to participate in scrap paper recycling.

The neighborhoods in Portland which are most likely to not participate in scrap paper recycling are shown on Map 6. These neighborhoods have both low education and low 
income levels and should therefore be the focus of future recycling campaigns which target nonparticipators.

Though only a few neighborhoods have the lowest levels of both education and income, Maps 4 and 5 may be used to extend conclusions about areas in Portland which may benefit from the targeting of recycling campaigns.

\section{DISCUSSION}

\section{Effect of Education on Scrap Paper Recycling Participation}

There are many reasons why education might affect a person's tendency to recycle scrap paper. The characteristics of people with different educational levels can vary greatly and influence whether or not they recycle.

This thesis found that having a college education positively affects an individual's likelihood to recycle. This probably relates to the fact that in the past, most environmental education was received in college, higher levels of schooling, or outside of the academic arena (Dodge 1990a; Dodge 1990b). Despite a recent upswing of environmental and recycling education in kindergarten through 12 grades (Elmer-Witt 1990; Nichols 1990; Bovet 1994; Hall 1994), most adults probably learned their environmental knowledge outside of school or in higher education. Bagby et al. (1992) found that people who understand how to recycle, actually recycle more material than people without that understanding. This may be tied 
to the finding that someone with a higher education is more likely to recycle scrap paper than someone without that education.

The finding that a college education is the dividing point between recyclers and nonrecyclers may be because it is probable that adults answered the Gargan survey and learned their environmental knowledge in higher education. The author speculates that if the survey in this thesis were given 20 years from now it would result in education having a much diminished effect on recycling participation. This is because the youth of today receives environmental education in grade school, which children are required to attend (Elmer-Witt 1990; Nichols 1990; Bovet 1994; Hall 1994). Results of this survey given in 20 years might either show education having a complete lack of effect on recycling participation or may show the recycling division at a much lower grade level.

The conclusion that education in general positively affects an individual's propensity to recycle may be tied to the fact that recycling education is now available from a variety of sources. Whether people today learn about recycling from pamphlets, television, lower education or higher education, it cannot be assumed that they received that education in college.

As youth learn about environmental issues in school, they are increasingly assuming greater responsibility for 
their behavioral choices such as waste reduction and recycling (Goldenhar and Connell 1993a). The Earth Works Group (1990) cited a study by Reynolds Aluminum which found that the actual practice of recycling positively changes attitudes towards recycling more than just studying the subject. Perhaps by actually recycling, people realize it is not that difficult or that much of an inconvenience. Children who grow up recycling and knowing about recycling, are also more likely to recycle and be committed environmental activists when older (Bovet 1994). Additionally, children educated about recycling may be influential on the recycling decisions of their parents (Elmer-Witt 1990; Bovet 1994; Messer 1994). These findings all support the idea that general recycling education positively affects recycling behavior.

Another explanation for the educational difference between recyclers and nonrecyclers could relate to environmentalism in college-age generations (Dodge 1990a; Dodge 1990b). Environmentalism has become somewhat of a trend, or fashion, with college campuses often serving as sites of environmental activism. People who attend college may have increased access to environmental education which can help explain the impact of education on recycling participation.

The findings that recycling participators tend to have higher educations than nonparticipators might also be 
related to literacy rates. Many forms of recycling education are communicated through written literature. Dyer Cabaniss (1993) reported $44 \%$ of recycling education to be in the form of print media. If an individual cannot read, or has trouble reading, the literature would most likely be disregarded. Lack of awareness about the importance of recycling or how to recycle could be a cause of nonparticipation in less educated segments of society.

Vining and Ebreo (1990) found that individuals with higher incomes and more education tended to receive their recycling information from newspapers while those with lower incomes and less education received information from school programs and television. If the same is true in Portland, it could help explain why those with lower educations and incomes tend not to recycle. Portland's main newspaper frequently runs articles about recycling (425 in 1994) (Oregonian Library Index on CD-ROM 1994), but recycling information is rarely on television (Becker 1995). Additionally, though Portland does have school recycling programs, people with lower educations, lower incomes and no prior experience in recycling may resist their childrens' demands to recycle more than people who have some recycling background. If people with lower educations and incomes are not in contact with sources of recycling education, it could contribute to the findings that they tend not to recycle. 
Also related to education, perhaps some nonrecyclers are recent immigrants to the United States who may not have had extensive educations and may have trouble with the English language. The 1990 Census reported that 1.98 of Portland's population were immigrants to the United States in the previous five years and $3.6 \%$ of Portland's entire population age five and older could not speak English well (Bureau of the Census 1993). Also in 1990, 7.78 of the Portland's population was foreign born (Office of Neighborhood Associations et al. 1993). If immigrants' previous education did not include environmental issues or if they are not able to read recycling literature written in English, they would probably not recycle. Promoting recycling on English speaking radio or television would not have an effect on immigrants who do not speak English. These factors may contribute to the findings that nonparticipators in scrap paper recycling tend to have lower educations than participators.

If a large portion of the immigrant population is college students, the above reasoning would not apply. Asian and Pacific Islanders and people of Hispanic origin make up the two largest foreign populations in Portland. Although $24.8 \%$ of Asian and Pacific Islanders, and $12.7 \%$ of Hispanics were enrolled in college in 1990, data is not available about the percentages of recent immigrants enrolled in college (Bureau of the Census 1993). 
Effect of Income on Scrap Paper Recycling Participation

This thesis found that, in addition to education's effect on scrap paper recycling, income also has an effect on an individual's propensity to recycle scrap paper. Someone with higher income is more likely to participate in scrap paper recycling than someone with lower income.

One explanation for the influence income has on the likelihood to recycle could relate to the fact that people with higher incomes probably have larger living spaces than people with lower income levels. Since lack of storage space is often cited as an excuse for not recycling (Bagby et al. 1992), it can be said that those with higher incomes and larger households would probably recycle, while those with lower incomes and smaller households would probably not recycle.

In many high density cities, people with higher incomes tend to live in expensive downtown apartments that might not have adequate recycling storage space. Portland has 9.6 housing units per acre in the small downtown area, but only 2.5 units per acre as a whole. Compared to many cities, this is a relatively low housing density (Office of Neighborhood Associations et al. 1993). This means that, unlike some places, people in Portland with high incomes probably do live in large homes. Since wealthy Portland residents probably have space to recycle, it could 
contribute to the findings that people with higher incomes tend to recycle.

Another explanation for the conclusion that people with higher incomes tend to recycle more than people with lower incomes could relate to perceptions about the environment and recycling. Everett and Peirce (1992) stated that environmental goods, such as the ability to recycle, appeal more to people with higher socioeconomic backgrounds. This thesis supports that notion. People with higher incomes may place great importance on environmental problems because they had the means to attend college, where they learned about environmental issues. Education and income were shown to be correlated strongly by Everett and Peirce (1992). Assumptions might be made that someone with a high income most likely has a high education and some knowledge of environmental issues as well.

People from the middle to the upper-middle class have historically been the most involved in the environmental movement (Everett and Peirce 1992). Everett and Peirce (1992) state that participation in voluntary organizations tends to increase with socioeconomic status. Conceivably, people with higher incomes may be able to devote more of their time to environmental concerns than people who have to work ceaselessly just to keep their heads above water. With higher salaries, wealthier people do not have to work 
as many hours as someone with lower income to receive equal pay.

People with higher incomes might also participate in environmental activities like recycling because they care about how they appear to others (Spaccarelli et al. 1990). Gruder-Adams (1990) suggested that the peer pressure of seeing neighbors' recycling bins at the curb could influence people to recycle. Since recycling is now generally considered the 'right' thing to do, people with higher incomes might feel more obligated to recycle than people with lower incomes who are more concerned with subsistence.

Those with high incomes might also tend to participate in scrap paper recycling more than those with low incomes because they have more materials to recycle. Studies have shown that people with higher incomes consume more (Phillips et al. 1984; Vining and Ebreo 1990; Katzev et al. 1993). Phillips et al. (1984) found that people with higher incomes consumed larger quantities of prepared foods than people with lower incomes. Since prepared foods usually have more packaging than fresh foods, those with higher incomes would have more food packaging scrap paper with which to dispose. Jacobs et al. (1984) found that those with higher incomes subscribe to more newspapers and magazines. Higher income households might also tend to have computers which generate a large amount of scrap 
paper. The consumption of large quantities of scrap paper might cause someone to recycle, whereas someone with less scrap paper would not bother to take the time.

Community stability could also contribute to people with higher incomes recycling scrap paper. Everett and Peirce (1992) found people with higher incomes tend to own their homes, stay in the community longer and thus be more involved in neighborhood issues such as recycling. This may be a factor contributing to the findings of this thesis. People in this study with higher incomes probably own their own homes, feel more neighborhood stability and recycle scrap paper.

The reasons above may explain why people with higher education and income levels might recycle more than people with lower education and income levels. The explanations try to untangle the complex psychology of why one person recycles when another does not. Hopefully these reasons provide clues which can be further studied to answer some of the intricate questions raised in this thesis. 
THE FUTURE OF SCRAP PAPER RECOVERY IN THE UNITED STATES

\section{Iegislation}

The Resource Conservation and Recovery Act (RCRA) of 1976 and the Comprehensive Environmental, Response, Compensation and Liability Act (CERCLA) of 1980 are two statutes at the federal level which govern waste management. Both of these statutes regulate hazardous waste disposal and sites. CERCLA is often called the Superfund law because it established a fund of money for the clean up of abandoned waste sites. RCRA regulates the handling of hazardous waste from the 'cradle to the grave,' or from its generation to its final disposal. RCRA is now being reauthorized by Congress and will probably include much broader measures concerning non-hazardous solid waste. RCRA could have broad effects on the future of solid waste management and recycling (Chilcote 1991).

Many bills have been introduced in both the House and the Senate for the reauthorization of RCRA. Senate Bill 976 and House Bill 3865 call for a "comprehensive national solid waste policy." The solid waste policy would include a mandated $25 \%$ recycling rate of municipal solid waste by 1995 and $50 \%$ by 2000. The policy also proposes a goal of $40 \%$ paper recovery by 1995, rising to 508 by 2000 (Boerner and Chilton 1994). With mandates such as this, scrap paper 
recovery could become a valuable part of many collection programs across the country.

Most recycling legislation occurs on state and local levels. There are three common types of supply-side recycling laws. Supply-side laws were generally the first types of legislation concerning recycling and focused on generating a supply of recovered materials for recycling. "Recycling plans" are laws that require local government to prepare a recycling plan which is often tied to a waste reduction or a recycling goal. A drawback to these laws is that the state does not explicitly require local governments to operate a recycling program. "Opportunity to recycle" is a requirement that local governments provide the opportunity to recycle through curbside collection, drop-off centers or processing recyclables from mixed waste. "Source separation" is a requirement that local governments mandate the source separation of one or more recyclables (Miller 1993).

Once supply-side legislation increased the supply of recyclables, recyclers found themselves at a loss for markets. As a result, laws which try to stimulate the demand for recovered materials are now increasing. Examples of common demand-side legislation are landfill bans and procurement policies for state and local agencies. By 1990, 40 states were offering grants and loans, tax incentives or other financial incentives to manufacturers 
that use recovered materials in processing and that develop markets for the end use of secondary materials (Ince and Alig 1992). In addition to legislative activities, sixteen states have created active recycling Market Development Councils. The councils serve as technical advisors to state legislators and help businesses develop markets for recycling (Miller 1994). Before any recycling is accepted and cost effective, there must be strong markets with demand for recyclables.

Other legislative actions encouraging demand for recyclables are minimum content laws. These laws specify that products such as newspaper, telephone directories, glass or plastic containers use a percentage of recovered material in their production. Twenty-eight states now have recycled content legislation or voluntary agreements for newsprint. These states account for $75 \%$ of the American newsprint market. It is probable that more states will follow this trend (Miller 1994).

Recovery and Utilization of Scrap Paper

The recovery rate of scrap paper is expected to rise nationwide and regionally for a variety of reasons. Curbside recycling programs and other opportunities to conveniently recycle scrap paper are increasing. Convenience has been shown to be a significant factor in raising recovery rates. Also, more mills are coming on 
for U.S. recovered paper has grown and is expected to continue this trend. Another factor promoting recovery rates is the Chicago Board of Trade's introduction of electronic trading of recovered paper. Easier marketing of the fiber may also prompt greater recovery (Metro 1993b).

As demand for products and packaging containing recycled paper increases, more paper materials will be diverted from the waste stream for recycling. Local collection programs, which create a supply of recyclables, assure mills a reliable source of material. Once a supply of recyclables is assured, mills are financially willing to accept recyclables. These market forces, coupled with increased virgin fiber costs, have made mill companies willing to spend the $\$ 1.1$ billion investment to convert to, or add recycling capabilities (Gill 1993).

Although the volume of recovered paper is increasing and more scrap paper is being used in paper production, mixed scrap paper is still not being utilized to its full extent. Mixed scrap paper represented $20 z$ of all the secondary fibers consumed domestically in the 1970s. Total domestic consumption of all waste paper has increased from approximately 14 million tons per year in the 1970 s to 20 million tons in 1989. Despite this, mixed scrap paper is still only $10 \%$ of the total domestic consumption (Apotheker 1990). In 1951, $32 \%$ of all paper produced in the United 
States came from waste paper. That rate today is about $29 \%$ (Davis 1992).

While one estimate stated that in 1991, there were seven recycling mills in the United States with the capacity to produce high-grade recycled printing and writing paper (Davis 1992), another said there were 404 mills in the United States and Canada (353 in the United States) (Sparks 1990). The difference in numbers lies in the definition of paper grade. The first estimate looked only at printing and writing paper manufacture, while the second considered all waste paper in the estimation.

The Pacific Northwest has a large and growing capacity for scrap paper utilization. Appendix F lists some uses for mixed scrap paper. Because of the large number of mills in Oregon and Washington (relative to the population base) and their great need for recovered paper, recovered fiber is drawn from sources as far away as Mississippi. Oregon and Washington account for less than $3 \%$ of the nation's population but supply 108 of the nation's paper and paperboard products. The two states produce about four times as much paper and paperboard as the region consumes (Gill 1993) .

As of 1993, there were 11 paper mills in Oregon and 17 in Washington. Eight of those mills either have plans to recycle paper, or already recycle paper. Paper mills in Oregon and Washington will almost triple their capacity for 
recovered paper in the six years between 1989 and 1995 (Gill 1993). Mills are investing in additional capacity for recovered paper now that they see a demand for recovered products and an insured supply of scrap paper.

Recovery Rates vs. Waste Diversion Rates

It is very important to recognize the distinctions in various recycling measurements. Recovery rates, diversion rates, recycling rates, capture rates, participation rates, setout rates and other measurements are all defined differently and can suggest particular details about a recycling program. Distinctions in communities, such as size of population, housing density, program length or size of service areas are also important factors to be aware of when evaluating a recycling program. Additionally, one must keep in mind that 'reported' participation in recycling may have very little reality in household garbage cans (Riley 1992).

Precise definition of terms is also critical (Riley 1992). Defining all terms and circumstances allows for rate comparisons to be made between communities. In 1990 for example, Glenn (1992) reported EPA estimates of $28.6 \%$, or 20.9 million tons, of paper and paperboard recovered from the municipal solid waste stream in the United States. Glenn (1992) also reported that the American Paper Institute (API) estimated 33.68, or 29 million tons, of 
paper and paperboard recovered in 1990. Definitions of wastepaper is what distinguished the two estimates. The API included both preconsumer and postconsumer paper and based its recovery rate on production of paper and paperboard products. EPA, on the other hand, used only postconsumer paper as the numerator and the amount of wastepaper estimated to be in the municipal waste stream as the denominator. This example draws attention to the fact that when analyzing rates, material definitions and methods of rate calculation must be closely considered to avoid misinterpretation.

\section{Recommendations}

Many suggestions can be made for solid waste managers who wish to encourage people to recycle scrap paper. Time and resources are needed to implement campaigns for recycling, but efforts across the United States have resulted in higher recovery rates (Dyer Cabaniss 1993; Bagby et al. 1992). Dyer Cabaniss (1993), found that the more educational methods used by recycling programs, the greater the number of per capita recyclables collected. Therefore, no one method should be relied upon to boost recovery.

This thesis found that people with low educational levels and low incomes tend to participate less in scrap paper recycling than those with higher levels. Recycling 
campaigns should therefore be targeted towards people with low education and income levels. In Portland, to maximize benefits of recycling efforts, recycling campaigns should be focused in the neighborhoods shown on Figure 9. These are the neighborhoods with both the lowest education and the lowest income levels in Portland. Since education was also found to have a greater effect on recycling participation than income, Figure 7 may be used to obtain more information about varying levels of education throughout the City.

Though most of the following recommendations focus on what can be done to increase participation by people of lower income and education levels, they are also effective for increasing recycling participation in all segments of society.

One method of increasing recycling participation is to begin school recycling education early. A child who grows up recycling will probably continue recycling as an adult (Bovet 1994). School workshops, puppet shows and other special programs which emphasize recycling can be used in schools to gain interest among the young. By stressing the importance of recycling early, students who might later quit school have already received some environmental education. However, for all people, learning environmental ideals in the early years of schooling may develop recycling into the standard method of dealing with waste. 
Community activities with readily available recycling information and recycling bins may play a great role in the development of recycling habits for all ages and backgrounds. Community events such as concerts, Earth Day, and environmental fairs can introduce people to recycling in a fun way, encouraging them to participate. Even if an event has nothing to do with the environment, witnessing others recycling may cause some people to emulate the envirommental behavior. The idea of doing good for ones' community can also be a strong motivator for recycling participation. Ties to the community may promote feelings of ownership causing people to care more about their environment.

Posting recycling information in unemployment agencies is another method of educating people of lower income levels. Though not everyone using job search agencies has a low income level, it may be assumed that the majority do. Learning about recycling is probably not the priority of most people in employment agencies, but there is at least a possibility of reaching someone while they are there. Posters are one inexpensive way to reach the low income segment of society.

Monetary incentives for recycling can be a form of targeting recycling campaigns towards people in the lower income bracket. People with low income levels might be more apt to take advantage of opportunities for monetary 
reward. Examples of incentives include raffles, prizes, tax credits or tax exemptions for participating in recycling. Depending on the reward, great response could result. Discounts on garbage hauling or rebates on disposal fees are other ideas for targeting recycling drives towards those who are not financially secure. Though monetary incentives and early recycling education are ideas which benefit people with lower income and lower education, people of all socioeconomic levels can profit from these efforts to increase recycling.

Recycling advertisements can also target people of low education and income levels. However, further research must be conducted in this area to determine how people of lower socioeconomic levels tend to receive their information. Vining and Ebreo (1990) found people with lower incomes and less education receive their information from school programs and television, while people with higher incomes and more education receive their information from newspapers. The Ontario Recycling Update (1985) reported television and newspaper to be the best ways to reach people not already looking for information on recycling. Radio was also recommended as a way to reach those 18-34 who tend to recycle less. Since Vining and Ebreo (1990) found a relationship between socioeconomic status and receipt of information, it is recommended that television and school programs be used as appropriate ways 
to target recycling education towards those of lower income and education levels.

Other economic incentives could also be used to encourage people to recycle. Fines for failure to recycle, or garbage hauler fee increases for more than one garbage can may cause people of lower income levels to make the effort to recycle. Though this incentive would affect people of all socioeconomic backgrounds, the impact might be felt more strongly on those with limited incomes.

Since nonparticipation in scrap paper recycling may be caused by language difficulty, it is also advised that services and materials be provided in languages besides English. Translated recycling information could be distributed to community centers and grocery stores in neighborhoods with high percentages of non-English speaking people. These tactics would allow non-natives to be educated about recycling service no matter what their socioeconomic level.

Aside from recommendations for recycling program strategies, further recycling research is strongly urged. One valuable study would be a measurement of the contamination level in collected scrap paper. Filtering contaminants out of scrap paper would allow greater profits to be incurred from its collection. A recommended study related to this thesis would be an inquiry of whether higher increments of socioeconomic level can be a predictor 
of higher increments of scrap paper recycling. It would also be interesting to discover if completing this study with a larger sample size or in a different city would change the results. Determining how long economic incentives continue to affect whether someone will recycle would also be an intriguing and useful study. Without doubt, there are unlimited possibilities for research in the area of solid waste management and recycling. 


\section{REFERENCES}

Adams, D. 1994. Assistant Solid Waste Planner, Metro Division of Solid Waste. Personal communication.

$\checkmark$ Anderson, P., Reindl, J. and Strasma, J. 1993. A new way to measure recycling effectiveness. Resource Recycling. $12(4): 83-92$.

$\checkmark$ Apotheker, S. 1993. Curbside recycling collection trends in the 40 largest U.S. cities. Resource Recycling. $12(12): 27-33$. - 1990. Mixed reviews for mixed paper. Resource Recycling. $9(1): 26-30,60-61$.

- Bagby, J., Diangson, T. and Patterson, G. 1992. Participation in Seattle's curbside recycling collection program. Resource Recycling. 11(12):64-71.

Bagby, J., Horne-Brine, P. and Morris, J. 1993. Looking into a crystal ball: what explains the value of recovered paper? Resource Recycling. 12(11):54-57.

Becker, C. 1995. Resource Director, Association of Oregon Recyclers. Personal communication.

Blalock, H.M. 1972. Social Statistics. New York, New York: McGraw-Hill Book Company.

Boerner, C. and Chilton, K. 1994. The folly of demand-side recycling. Environment. 36(1):7-17.

Bovet, S.F. 1994. Teaching ecology: a new generation influences environmental policy. Public Relations Journal. $50(4): 24-27$.

Brachman, S., Engelbart, M. and Duff, A. 1993. Apartments generate more recyclables. Biocycle. $34(7): 66-67$.

Bureau of the Census. 1993. 1990 Census of Population and Housing. Washington, DC:U.S. Government Printing Office, Bureau of Census, U.S. Department of Commerce. 
Bureau of Environmental Services. undated. Recycle it at the Curb! (pamphlet). Portland, OR: Bureau of Environmental Services.

- 1994. Management Report for Solid Waste and Recycling. January 1994. Portland, OR: Bureau of Environmental Services.

- 1993. City of Portland-Administrative Rules. December 1993. Portland, OR: Bureau of Environmental Services.

- 1990. Interim Report to Council on the Status of the Solid Waste Collection System in Portland. August 1990. Portland, OR: Bureau of Environmental Services.

Burn, S.M. and Oskamp, S. 1986. Increasing community recycling with persuasive communication and public commitment. Journal of Applied Social Psychology. $16(1): 29-41$.

Chilcote, N.A. 1991. The rising costs of municipal landfills. American City and County. 106(10):40-46.

Cohen, D. 1978. Separate Collection Programs, A National Survey. Washington, DC: United States Environmental Protection Agency.

Davis, A. 1992. The paper industry could do more. Pulp and Paper. $66(8): 102$.

De Blij, H.J. 1987. The Earth. New York, NY: John Wiley and Sons.

De Young, R. 1984. Motivating people to recycle: the use of incentives. Resource Recycling. 3(2):14-16.

Dodge, S. 1990a. More college students choose academic majors that meet social and environmental concerns. The Chronicle of Higher Education. 37(14):A1-A3. - 1990b. A course on managing the earth attracts students at Kalamazoo. The Chronicle of Higher Education. $37(14):$ A32 .

Dyer Cabaniss, A. 1993. Recycling education: the critical link. Resource Recycling. 12(2):62-65.

Earth-Works Group. 1990. The Recycler's Handbook. Berkeley, CA: Earth-Works Press. 
Elmer-Witt, P. 1990. The ecokid corps: school-age crusaders can be a pain in the neck, but they may be the best hope for the cause of preservation. Time. 136(27):51.

Everett, J.W. and Peirce, J.J. 1992. Social networks, socioeconomic status, and environmental collective action: residential curbside block leader recycling. Journal of Environmental Systems. 21(1):65-84.

Folz, D.H. 1991. Recycling program design management, and participation: a national survey of municipal experience. Public Administration Review. 51 (3):222231 .

Fountain, R. 1995. Director of the Statistics Consulting Laboratory, Portland State University. Personal communication.

Friberg, T. 1993. Alternative uses for recovered paper. Resource Recycling. $12(1): 26-33$.

Gaile, G.L. and Willmott, C.J., ed. 1989. Geography in America. Columbus, $\mathrm{OH}$ : Merrill Publishing Company.

Gill, K.E. 1993. Paper recycling capacity in the Pacific Northwest. Resource Recycling. 12(1):55-63.

Glenn, J. 1992. Paper recycling approaches prime time. Biocycle. $33(10): 46-53$.

Goldenhar, L.M. and Connell, C.M. 1993a. Understanding and predicting recycling behavior: an application of the theory of reasoned action. Journal of Environmental Systems. $22(1): 91-103$.

and 1993b. Effects of educational and feedback interventions on recycling knowledge, attitudes, beliefs, and behaviors. Journal of Environmental Systems. $21(4): 321-333$.

Goldstein, N. 1992. Adding paper to the mix. Biocycle. $33(8): 54-8$.

Gruder-Adams, S. 1990. Recycling participation assessment. Biocycle. $31(9): 38-43$.

Hall, P.L. 1994. "Green" issues rise on national agenda. Public Relations Journal. $50(4): 22-23$.

Haynes, R.W. 1989. Effects of waste paper recycling on the forest sector. Resource Recycling. 8(7):44-46, 62 . 
Ince, P.J. and Alig, J.T. 1992. Waste paper recycling and the future timber market. Resource Recycling.

$11(4): 123-131$.

Jacobs, H.E., Bailey, J.S. and Crews, J.I. 1984. Development and analysis of a community-based resource recovery program. Journal of Applied Behavior Analysis. $17(2): 127-145$.

Katzev, R.D., Blake, G. and Messer, B. 1993. Determinants of participation in multi-family recycling programs. Journal of Applied Social Psychology. $23(5): 374-385$.

Katzev, R.D. and Pardini, A.U. 1987. The comparative effectiveness of reward and commitment approaches in motivating community recycling. Journal of Environmental systems. $17(2): 93-113$.

Katzev, R.D. and Wang, T. 1994. Can commitment change behavior? Journal of Social Behavior and Personality. 9 (1) : 13-26.

Kuniholm, P.F. 1990. Accurate estimates for recycling. Biocycle. $31(7): 70-73$.

Lehmann, E.L. 1975. Nonparametrics. Oakland, CA:Holden-Day Inc.

Marascuilo, L.A. and Serlin, R.C. 1988. Statistical Methods for the Social and Behavioral Sciences. New York, $\mathrm{NY}:$ W.H. Freeman and Company.

Massie, K. 1994. Associate Solid Waste Planner, Metro Division of Solid Waste. Personal communication.

McGuire, R.H. 1984. Recycling. American Behavioral Scientist. $28(1): 93-114$.

Mellander, R. 1991. Waste reduction on Vancouver Island. Biocycle. $32(3): 74$.

Messer, B. 1994. Assistant Professor, Center for Urban Studies, Recycling Education Project. Personal communication. - 1993. Personal communication.

Metro. 1994. Metro 1993-94 waste characterization study preliminary results-Fall sorting season. Portland, OR: Metro. 
- 1993a. Metro's 1992 Recycling Level Survey Results. April 1993. Portland, OR: Metro.

- 1993b. 1992/93 Mixed Scrap Paper Market Profile.

Äugust 1993. Portland, OR: Metro.

- 1993c. Solid Waste Information system. Includes

actual data through June 1993. Portland, OR: Metro.

- 1992. Metro Recycling Level Survey 1991. Portland,

OR: Metro

- 1989. Regional Waste Reduction Plan. Portland, OR: Metro.

Miller, C. 1994. Recycling it the states: 1993 update. Waste Age. 25(3):61-70.

- 1993. Recycling. Waste Age. $24(10): 26-34$.

Miller Jr., G.T. 1987. Living in the Environment. Belmont, CA: Wadsworth Publishing Company.

Neter, J. Wasserman, W. and Kutner, M.H. 1989. Applied Linear Regression Models. Boston, MA:Richard D. Irwin Inc.

Nichols, M. 1990. The green generation: schools are the new centers for activism. Maclean's. 103(38):90-92.

Norusis, M.J. 1990. SPSS Base System User's Guide. Chicago, II:SPSS Inc.

Nowaczyk, R. 1988. Introductory Statistics for Behavior Research. New York, NY:Holt, Rinehart and Winston, Inc.

Office of Neighborhood Associations, City of Portland and Center for Urban Studies at Portland State University. 1993. Portland Neighborhood Information Profiles. Portland, OR:Center for Urban Studies and Office of Neighborhood Associations.

Ontario Recycling Update. 1985. Everything you ever wanted to know about recyclers. Ontario Recycling Update. $5(3): 5$.

Oregon Department of Transportation. 1993. Demographic and Economic Forecasts 1990-2030. Salem, OR: Oregon Department of Transportation. 
Oregon State Employment Division. 1982. Annual Economic

Report, 1982 Portland Standard Metropolitan Statistical Area. Salem, OR: Oregon State Employment Division.

Oregonian Library Index on CD-ROM. 1994. Branford P. Millar Library, Portland State University.

Pardini, A.U. and Katzev, R.D. 1984. The effect of strength of commitment on newspaper recycling. Journal of Environmental systems. 13(3):245-254.

Phillips Jr., D.A., Restrepo, I. and Rathje, W.L. 1984. El proyecto basura. American Behavioral Scientist. $28(1): 139-153$.

Platt, B., Doherty, C., Broughton, A.C., and Morris, D. 1991. Beyond 40 Percent. Washington, D.C.: Institute for Local Self-Reliance.

Riley, B. 1992. Evaluation of curbside recycling programs. Biocycle. $33(10): 68-70$.

Rogoff, M.J., Embree, W. and Stone-Franklin, R. 1992. Waste stream analysis: what it means for recycling programs. Public Works. $123(5): 42-44$.

Rubenstein, J.M. 1994. An Introduction to Human Geography. New York, NY: Macmillan Publishing Company.

Simmons, I.G. 1991. Earth, Air and Water. London, England: Edward Arnold.

- 1981. The Ecology of Natural Resources. New York, NY: John Wiley and Sons.

Skitt, J. ed. 1992. 1000 Terms in solid Waste Management. Copenhagen, Denmark: ISWA.

Spaccarelli, S., Zolik, E. and Jason, L. 1989. Effects of verbal prompting and block characteristics on participation in curbside newspaper recycling. Journal of Environmental Systems. 19(1):45-57.

Sparks, E. 1990. Dynamics affecting future waste paper markets. Resource Recycling. 9(1):20-22.

Sudol, F.J. and Zach, A.L. 1991. Newark's curbside recycling program: a participation rate study. Resources, Conservation and Recycling. 5:35-45. 
Tableman, M. 1995. Assistant Professor, Mathematical Science Department, Portland State University. Personal communication.

Vining, J. and Ebreo, A. 1990. What makes a recycler? A comparison of recyclers and nonrecyclers. Environment and Behavior. 22 (1):55-73.

Wagner, R.H. 1978. Environment and Man. New York, NY: W.W. Norton and Company, Inc.

Walker, B. 1994. Recycling Program Manager, City of Portland, Bureau of Environmental Services. Personal communication.

Wang, T.H. and Katzev, R.D. 1990. Group commitment and resource conservation: two field experiments on promoting recycling. Journal of Applied Social Psychology. 20(4):265-275.

Weigel, R.H. 1977. Ideological and demographic correlates of proecology behavior. Journal of Social Psychology. $103: 39-47$.

Wilcox, R.R. 1987. New Statistical Procedures for the Social Sciences. Hillsdale, NJ:Lawrence Erlbaum Associates, Publishers.

Wineberg, H. 1993. Population Estimates for Oregon: July 1,1992. Portland, OR: Center for Population Research Census. 


\section{APPENDIX A}

DEFINITIONS OF TERMS IN SOLID WASTE MANAGEMENT AND RECYCLING Sources: Apotheker 1990; Skitt 1992. 
Divert: To prevent waste from entering a landfill by recycling.

Mixed-grade scrap paper or mized-grade waste paper: A mixture of various qualities of paper which are not limited as to type of packing or fiber content.

Post-consumer product: A product that has gone through its useful life and has been discarded by the user.

Recovery: Separation and collection of recyclable material from waste.

Recycling: The reuse of materials, not necessarily in their original forms.

8etout: Placing recyclable materials at the curb for curbside collection.

8olid waste: Any refuse or waste material. Includes semisolid sludges produced from domestic, commercial or industrial sources or processes including mining and agricultural operations and water treatment plants.

sorting: The manual separation and extraction of salvageable material from solid waste.

8ource separation: The process of removing recyclables from the waste stream for recycling. 


\begin{abstract}
APPENDIX B
PRELIMINARY RESULTS OF METRO'S 1993-1994 WASTE CHARACTERIZATION STUDY
\end{abstract}

Source: Metro 1994:2. 


\begin{tabular}{|c|c|c|c|c|c|c|c|}
\hline & \multirow[b]{2}{*}{$\begin{array}{c}\text { All } \\
\text { Generators }\end{array}$} & \multirow[b]{2}{*}{ Residential } & \multicolumn{2}{|c|}{ Sources of Waste Generation } & \multirow[b]{2}{*}{ Industrial } & \multirow[b]{2}{*}{ Construction } & \multirow[b]{2}{*}{ Mixed } \\
\hline & & & $\begin{array}{c}\text { Residential } \\
\text { Self-Haul }\end{array}$ & Commercial & & & \\
\hline \multicolumn{8}{|l|}{ Waste Type } \\
\hline Writing Paper & $12.57 \%$ & $16.37 \%$ & $8.49 \%$ & $15.88 \%$ & $10.51 \%$ & $1.80 \%$ & $16.29 \%$ \\
\hline $\begin{array}{l}\text { Hand Cover Books } \\
\text { High Grade Paper } \\
\text { Low Grade Paper } \\
\text { Magazines } \\
\text { Newspaper } \\
\text { Nonrecyclable Paper } \\
\text { Paper Packaging }\end{array}$ & $\begin{array}{l}0.08 \% \\
2.68 \% \\
2.31 \% \\
2.33 \% \\
2.39 \% \\
2.80 \% \\
12.06 \%\end{array}$ & $\begin{array}{c}0.05 \% \\
2.74 \% \\
3.50 \% \\
3.03 \% \\
3.61 \% \\
3.45 \% \\
10.65 \%\end{array}$ & $\begin{array}{l}0.00 \% \\
0.73 \% \\
2.13 \% \\
4.16 \% \\
0.71 \% \\
0.76 \% \\
9.92 \%\end{array}$ & $\begin{array}{l}0.22 \% \\
4.23 \% \\
2.71 \% \\
2.39 \% \\
2.61 \% \\
3.71 \% \\
17.24 \%\end{array}$ & $\begin{array}{l}0.09 \% \\
2.87 \% \\
1.53 \% \\
0.87 \% \\
1.65 \% \\
3.50 \% \\
17.16 \%\end{array}$ & $\begin{array}{l}0.00 \% \\
0.20 \% \\
0.20 \% \\
1.16 \% \\
0.20 \% \\
0.14 \% \\
6.94 \%\end{array}$ & $\begin{array}{r}0.04 \% \\
3.43 \% \\
2.73 \% \\
2.71 \% \\
3.55 \% \\
3.83 \% \\
11.85 \%\end{array}$ \\
\hline $\begin{array}{l}\text { Bleached Boxboand } \\
\text { Cardboard/Brown Bags } \\
\text { Mixed Paper } \\
\text { Recyclable Paper } \\
\text { Nonrecyclable Paper }\end{array}$ & $\begin{array}{l}0.40 \% \\
6.84 \% \\
1.41 \% \\
2.18 \% \\
1.22 \%\end{array}$ & $\begin{array}{l}0.59 \% \\
4.42 \% \\
0.98 \% \\
3.50 \% \\
1.17 \%\end{array}$ & $\begin{array}{l}0.37 \% \\
6.74 \% \\
0.78 \% \\
1.75 \% \\
0.29 \%\end{array}$ & $\begin{array}{c}0.48 \% \\
10.29 \% \\
1.98 \% \\
2.26 \% \\
2.23 \%\end{array}$ & $\begin{array}{l}0.14 \% \\
11.99 \% \\
2.21 \% \\
1.09 \% \\
1.72 \%\end{array}$ & $\begin{array}{l}0.01 \% \\
4.62 \% \\
0.71 \% \\
0.49 \% \\
0.11 \%\end{array}$ & $\begin{array}{l}0.57 \% \\
5.70 \% \\
1.86 \% \\
2.63 \% \\
1.09 \%\end{array}$ \\
\hline \multicolumn{8}{|c|}{$\begin{array}{l}\text { "Residential Self-Haul = waste hauled to disposal facilities in private vehicles } \\
\text { from single and multi-family housing units. } \\
\text { "Mixed = Loads containing } 75 \% \text { or less of waste generated from residential, } \\
\text { commercial or industrial sources. }\end{array}$} \\
\hline
\end{tabular}




\section{APPENDIX C}

RECYCLE IT AT THE CURB!

Source: Bureau of Environmental Sevices. undated pamphlet. 


\section{Recycle It At The Curb!}

Finally there's a solution, and you don't even have to leave home. Get out from :'nder that pile.lt's easy.

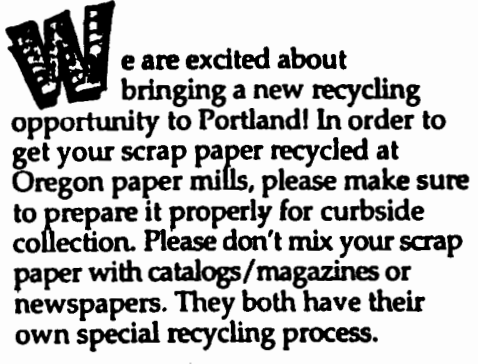

own special recycling process.

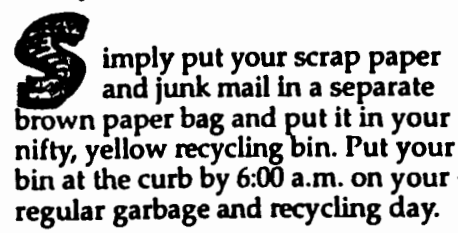

Questions?

Need more information? Call the Portland Curbside Hotlline at 823-7202

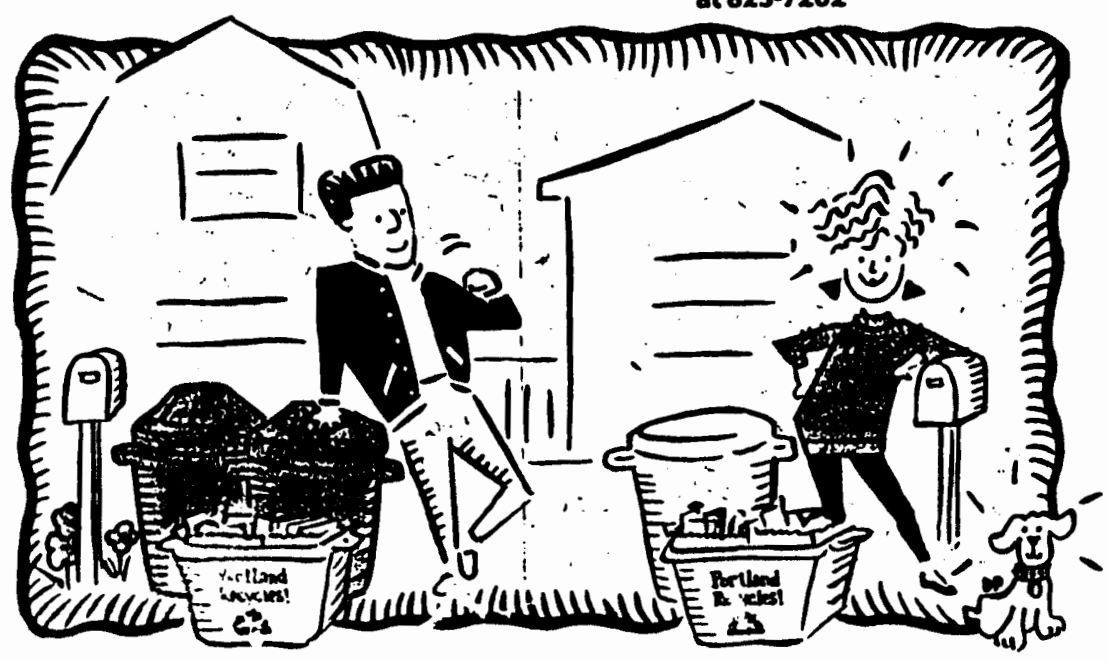

Herés a list of what you can and cannot recyde curbside. When in doubt, don't set it out. If you want to know why something can't be recycled, call us and we'll explain. Keep this list handy to remember what can and cannot be recycled.

\section{DORECYCLE] \\ DONTRECYCLI]}

"Junk" Mall

Post-lt Notes

Paper Egg Cartons

Shoe Boxes, flattened

Billinserts

Brochures (like this one)

Errvelopes (sticky labels and windows are okay)

Paper Bags, white or colored

Cereal and Cracker Boxes, flattened (remember to remove linings)

Paper Cores (without the paper towels or toilet paper, please)

Paper Labels (from the tin cans you

$$
\text { recycled) }
$$

Greeting Cards (no foil cands)

Wrapping Paper (no foil paper)

Paper; copy and lax paper; colored and white paper; household, note, and

computer paper; file folders and coupons.

Keep scrap paper separate from your other recyclables. If your recyclables are mixed together, they will not be picked up.

\section{You can recycle all of the} above items.
Waved Paper or Boxes

Cereal Box Uners (this is waxed paper and

not good for recycling)

Food Contaminated Containers

Milk Cartons, Juke Cartons

Frozen Food Boxes

Disposable Diapers

Pet Food Bags

Photographs

Foll, Tape, String

Paper Plates

Frozen Julce Paper Cans

Tissues, Napkins or Paper Towels

Foam Packing Materials

Lottery Scratch-offTlickets

Plastic Type Papers Used for Express

Mall Envelopes

Phone Books

Hard Cover Books

Carbon Paper

There are some things that aren't good for the recycling process, so please remember not to include them in your scrap paper recycling bag.

Please, no piastics of any kind. 
APPENDIX D

GARGAN SURVEY QUESTIONNAIRE OF RESIDENTIAL WASTE DISPOSAL AND RECYCLING IN PORTIAND, OREGON 
Hello, This is with Gargan Research, a local market research company. Today/tonight we are calling on behalf of Metropolitan Service District. We are conducting a survey about recycling and we would like to include your household's opinions.

May I please speak to the male or female head of the household who is most responsible for recyciing? (IF EQUALLY RESPONSIBLE CONTINUE AND IF NOT AVAIIABLE SCF. EDULE CALL BACK TIME)

RELATE NUMBER

GENDER

Male.....

Female...
[1] 1

1. Since last September, has your garbage service been interrupted due to... (READ EACH RESPONSE AND RECORD ANSWER)

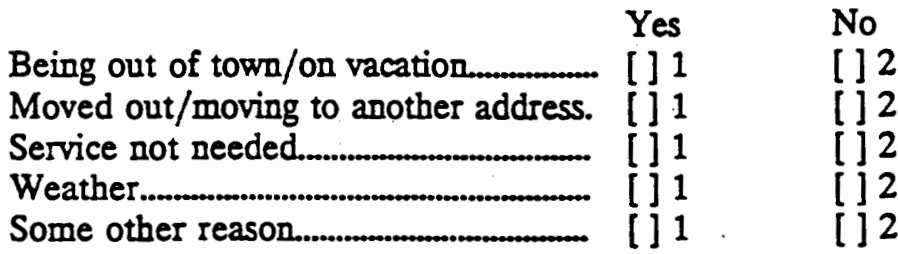

2. Has the level of your garbage service changed anytime since last September? By level of service I mean the size of the can, the mumber of cans used or the frequency of pick-up.

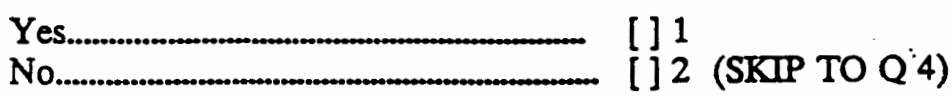

3. How has your level of service changed, have you.... (READ LIST \& RECORD ALL THAT APPLY)

Increased can size [ ] 1

Decreased can size

Increased frequency of pick-up............................ [ [ ] 3

Decreased frequency of pick-up...................... [ ] 4

Increased number of cans put at the curb........... [ ] 5

Decreased number of cans put at the curb.......... [ ] 6 
4. Which of the following materials do you recycle. This inciudes material you put out at the curbside as well as items you take some place else. (READ LIST, ROTATE STARTING ORDER)

5. (FOR EACH TTEM MARKED "YES" IN Q4, ASK) Thinking of all of the else?

you recycle, what percentage do you recycle at the curb verses taking someplace

(ENTER AS WHOLE PERCENI' IF RESPONDENT CANNOT EASILY GIVE PERCENT ASK:) Could you answer suing the following categories? - up to one fourth, one-fourth to one-half, one-half to three-fourths or more than three-fourths.

\section{RECYCLE}

O4
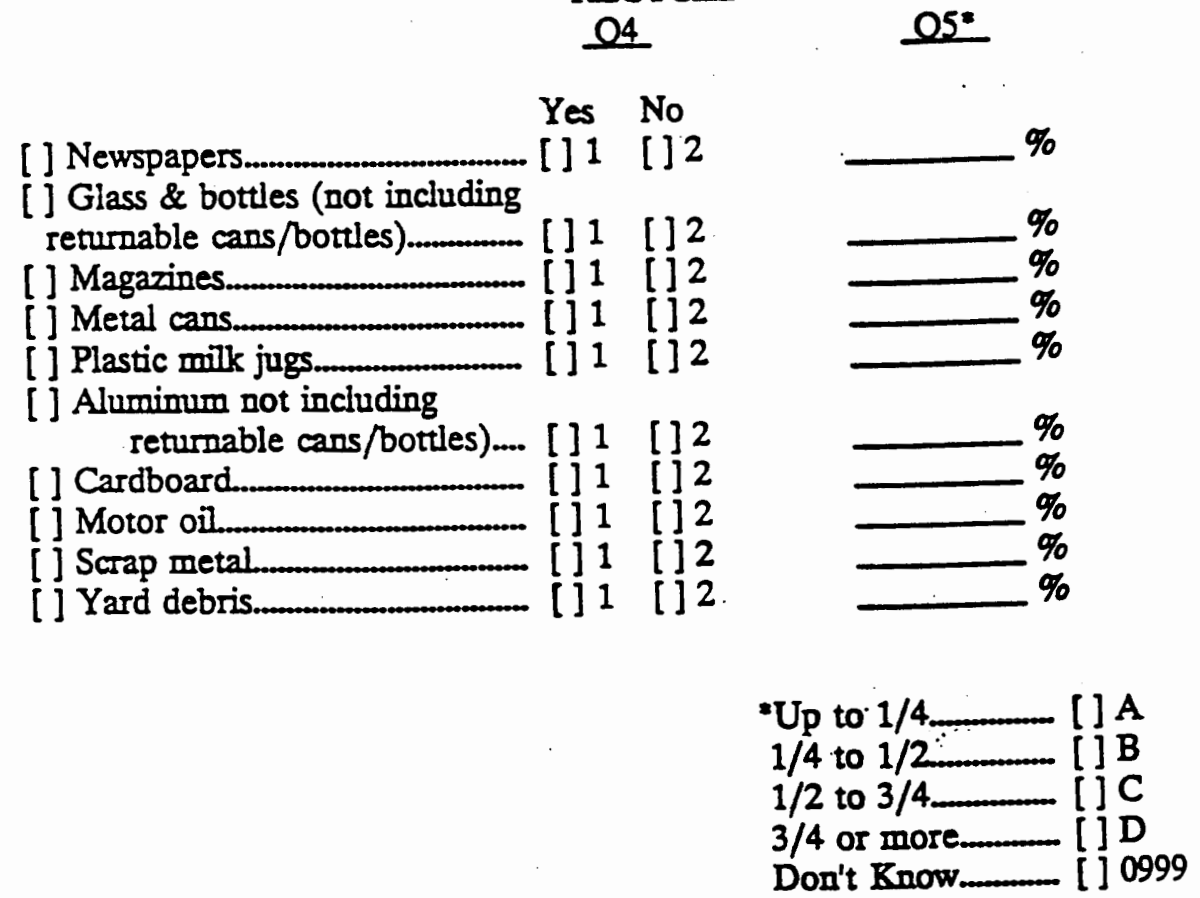

6. Do you take your garbage to another location rather than leaving it at the curb?

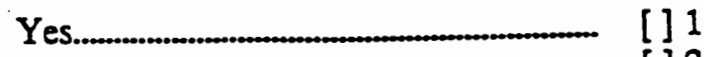

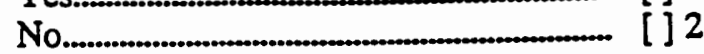


7. Have you or anyone used a drop box, dumpster, truck or some other method to dispose of any debris at your bouse anytime since September of last year? This would include the disposal of any debris, refuse or waste material from or around your home.

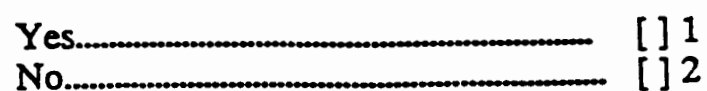

\section{HOUSEHOLD INFORMATION}

Now, I would like to ask you some questions about the characteristics of your housebold. The answers you give will be used only for grouping your responses with other households and will be kept strictly confidential.

8. Do you own or rent you home?

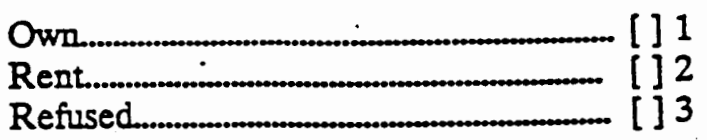

9. Is this a single family dwelling, a duplex or a multiple unit dwelling?

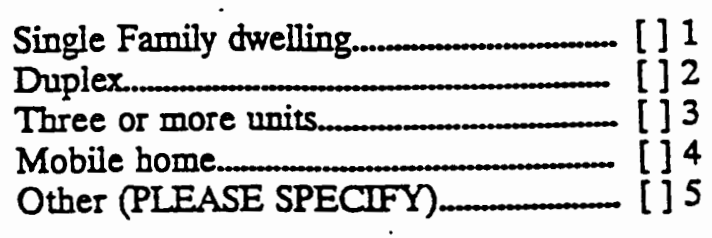

Refused_[16

10. How many bedrooms are there in your dwelling? (DC NOT READ LIST, RECORD ONLY ONE RESPONSE)

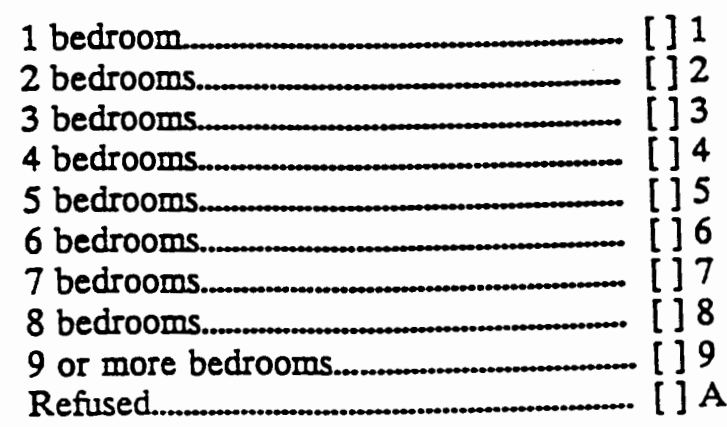


11. Does your dwelling have a basement? How about an attached or enclosed garage?

$\begin{array}{llll}\text { Bes } & \text { No Refused } \\ \text { Basement................................ [ ] } 1 & \text { [ ] } 2 & \text { [ ] } 3 \\ \text { Attached or enclosed garage...... [ ] } 1 & \text { [ ] } 2 . & \text { [] } 3\end{array}$

12. Including yourself, bow many people are living in your household at this time? (DO NOT READ LIST)

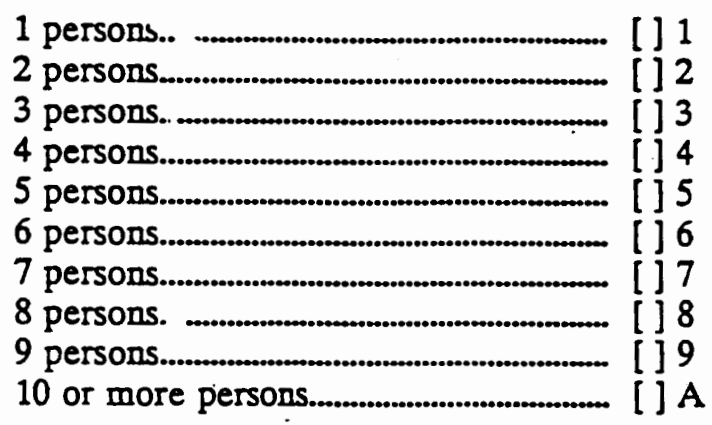

13. Which of the following statement best describes any changes in your housebold size over the last 8 months? Since September of last year, the mumber of people living at my current address has...(READ LIST, RECORD ONLY ONE RESPONSE)

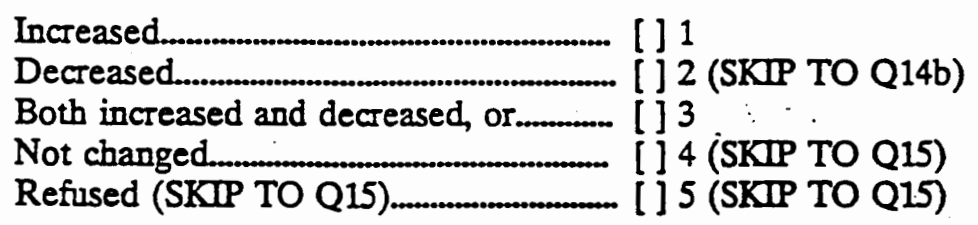

14a By how many people has your household increased since last September? (RECORD RESPONSE, DO NOT ACCEPT A RANGE).

INCREASED BY PEOPLE

14b. By how many people has your household decreased since last September? (RECORD RESPONSE, DO NOT ACCEPT A RANGE)

DECREASED BY PEOPLE

15. Are there any members of your household who live there only a part of the year? How many? (RECORD EXACT NUMBER OF TEMPORARY HOUSE HOLD MEMBERS)

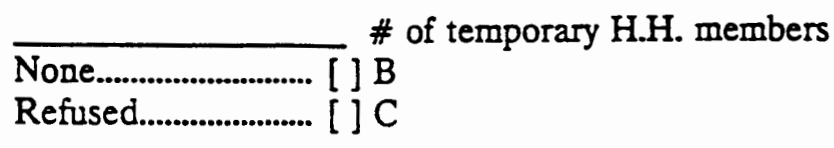


16. Starting with the youngest member, tell me the gender and age of each person currently living in you housebold. Please remember to include yourself.

(IF RESPONDENT IS REFUSES TO GIVE AGE HAND THEM CARD "A" AND ASK FOR RANGES)

(FOR ALL HOUSEHOLD MEMBERS AGE 25 + ASK Q17 OTHERWISE SKIP TO Q18)

17. (HAND CARD "B" TO F.ESPONDENT AND ASK..) What is the highest level of education has completed? (RECORD CODE IN UNDER COLUMN Q17) GEN-

\begin{tabular}{|c|c|c|c|c|c|}
\hline & $\mathrm{DER}$ & REFUSED & AGE & REFUSED & Q17 \\
\hline PERSON 1.... & & {[] 3} & & [ ] $0999 *$ & \\
\hline PERSON $2 \ldots$ & & {$[j 3$} & & [ ] 0999 & \\
\hline PERSON $3 . . . . . . . . . . . . .$. & & {[] 3} & & [ ] 0999 & \\
\hline PERSON 4................... & & {$[3$} & & [ ] & \\
\hline PERSON $5 \ldots$ & & ij3 & & [jo999 & \\
\hline PERSON 6 & & {$[j 3$} & & [ j0999 & \\
\hline PERSON $7 \ldots$ & & {$[3$} & & 10999 & \\
\hline PERSON 8.................... & & {[] 3} & & [ 10999 & \\
\hline PERSON 9.............. & & {[] 3} & & [ 10999 & \\
\hline PERSON 10............. & & {$[j 3$} & & [ ] 0999 & \\
\hline
\end{tabular}

AGE RANGE CODES

EDUCATION CODES

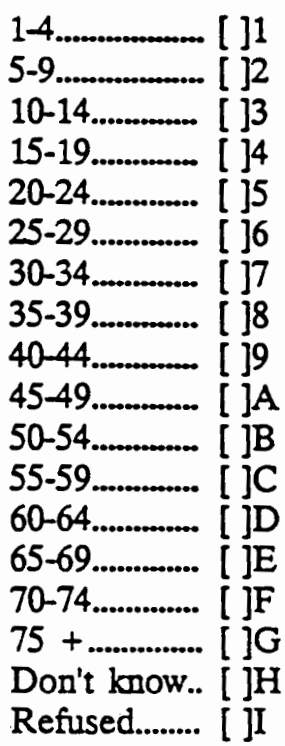

Less than high school........ [ ]1

High school graduate........ [ ] 2

Some college/tech school.. [ ]3

College grad._._._. [ ] $] 4$

Post baccalaureate............... [ ]

Don't know._._................ [ ] 6

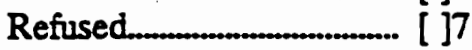

$35-39 \ldots \ldots . . . . . . . . .[]$

40-44............ [ ] $] 9$

$45-49 \ldots \ldots \ldots$

$50-54 \ldots \ldots \ldots . . . . . . .[] B$

$55-59 \ldots \ldots \ldots . . . . . . .[] \mathrm{C}$

$60-64 \ldots \ldots \ldots \ldots$ [ ] ]D

$65-69 \ldots \ldots \ldots . . . . . . .[] E$

70-74............ [ ] ]F

$75+\ldots . . . . . . . . . .[] \mathrm{G}$

Don't know.. [ ] 
18. Has your family moved from another residence into your current address since September of last year?

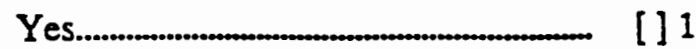

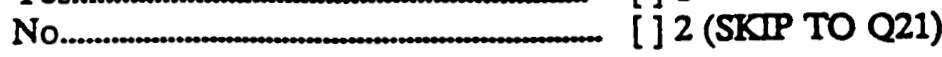

19. When did you/your family move into the house you are carrently living in now? (RECORD MONTH, DAY \& YEAR - OBT.INN BEST ESTIMATE)

Month

Don't know

Day

[ ] 0999

Year

[ ] $] 0999$

[] 0999

20. Can you tell me how many people were livi-g in this house before you moved in?

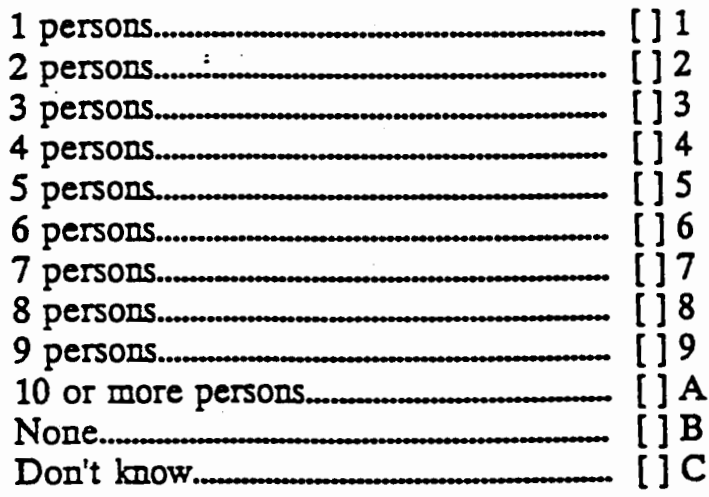


21. Thinking of all the people in your bome and all the sources of wages and other income, what your annual household income to the nearest thousand dollars? (ENTER AMOUNT)

$$
\text { S }
$$
(SKIP TO CLOSING)

Refused (DO NOT READ) [ ] 0999

21a. (HAND CARD "C" TO RESPONDENT AND ASK.) Which of the following ranges does your annual household income fall into? (RECORD RESPONSE)

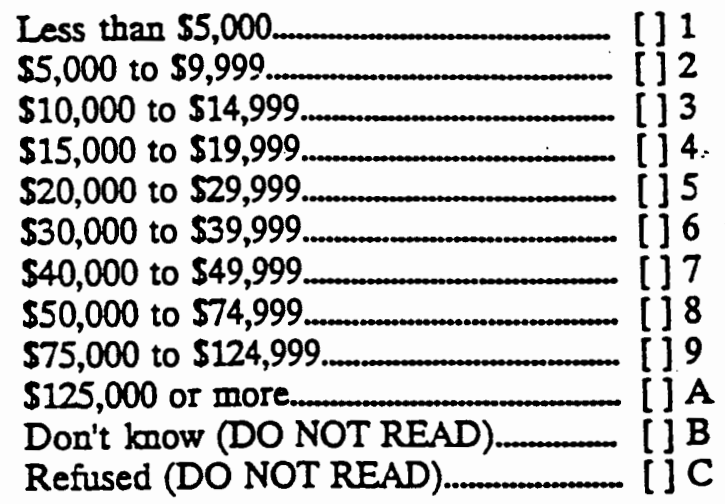

Those are all the questions I have, so that my supervisor can verify that I completed this survey may I have your name?

NAME

STREET ADDRESS

PHONE NUMBER

DATE OF INTERVIEW

Thank you for your participation in our study! 
APPENDIX E

REFUSE AND RECYCLING WEIGHT LOG SHEETS FOR SINGLE-FAMILY CONTAINER WEIGHT STUDY IN PORTIAND, OREGON 


\begin{tabular}{|c|c|c|}
\hline \multirow{3}{*}{$\begin{array}{l}\text { Service Level } \\
\text { Column 1: frequency } \\
W=\text { weekly } \\
M=\text { monthly } \\
\text { CB = call basis } \\
N S=\text { no service } \\
O=\text { other } \\
\text { "circle frequency code } \\
\text { if service if off curb }\end{array}$} & \multicolumn{2}{|l|}{ Weight Log Codes } \\
\hline & Column 2: volume & \\
\hline & $\begin{array}{l}20=20 \text { gallon } \\
32=32 \text { gallon } \\
40=35-40 \text { gallon } \\
60=60 \text { gallon } \\
90=90 \text { gallon }\end{array}$ & \\
\hline $\begin{array}{l}\text { Container Description } \\
\text { Column 1: type }\end{array}$ & Column 2: color & Column 3: distinguishing marks \\
\hline $\begin{array}{l}\mathrm{mp}=\text { mini can plastic } \\
\mathrm{mm}=\text { mini can metal } \\
\mathrm{sp}=\text { standard can plastic } \\
\mathrm{sm}=\text { standard can metal } \\
\mathrm{pb}=\text { plastic bag ( } 32 \text { gal) } \\
\mathrm{rb}=\text { recycling bin (14 gal) } \\
\mathrm{kb}=\text { kb bag (32 gal) } \\
\mathrm{rc}=\text { roll cart } 32 \text { gal. } \\
\mathrm{r}=\text { roll cart } 35-40 \text { gal. } \\
\mathrm{r} 2=\text { roll cart } 60 \text { gal. } \\
\mathrm{r} 3=\text { roll cart } 90 \text { gal. } \\
\mathrm{bu}=\text { bundle } \\
\mathrm{mc}=\text { milk crate } \\
\mathrm{bk}=\text { bucket } \\
\mathrm{o}=\text { other }\end{array}$ & $\begin{array}{l}g r=\text { green } \\
g y=\text { gray } \\
b l=\text { blue } \\
b r=\text { brown } \\
b g=\text { beige } \\
o g=\text { orange } \\
y l=\text { yellow } \\
0=\text { other }\end{array}$ & $\begin{array}{l}\text { nu }=\text { brund new } \\
b_{r}=\text { broken down } \\
\text { ut }=\text { unmatching top } \\
\text { vo = very old } \\
0=\text { other }\end{array}$ \\
\hline Recycling Material & & \\
\hline $\begin{array}{l}\mathrm{NP}=\text { newspaper } \\
\mathrm{CG}=\text { clear glass } \\
\mathrm{GG}=\text { green glass } \\
\mathrm{TN}=\text { tin } \\
\mathrm{AL}=\text { aluminum } \\
\mathrm{CB}=\text { cardboard } \\
\mathrm{MJ}=\text { milk jug } \\
\mathrm{Mg}=\text { magazine } \\
\mathrm{OI}=\text { motor oil } \\
\mathrm{Me}=\text { scrap metal } \\
\mathrm{GB}=\text { gray board } \\
\mathrm{SP}=\text { scrap paper } \\
\mathrm{O}=\text { other }\end{array}$ & & \\
\hline
\end{tabular}




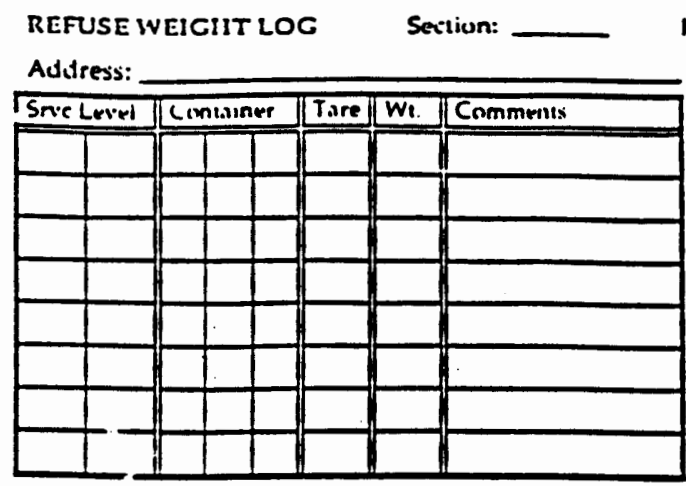

Address:

Hauler:

Page ___ of ___

Address:

\begin{tabular}{|c|c|c|c|c|}
\hline Snor Level & Comtainet & Tare & IVI. & Comn:enis \\
\hline & & & & \\
\hline & & & & \\
\hline & & & & \\
\hline & & & & \\
\hline & & & & \\
\hline & & & & \\
\hline & & & & \\
\hline & & & & \\
\hline
\end{tabular}

Address:

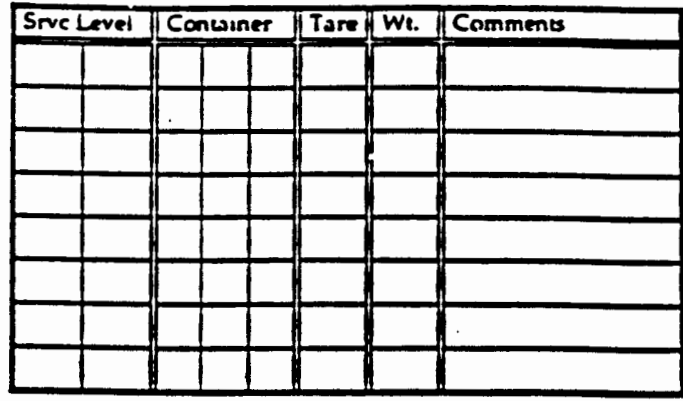

Address:

- Address:

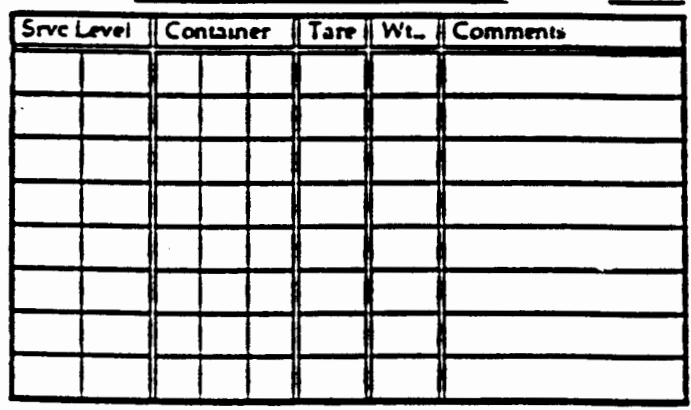

Address:

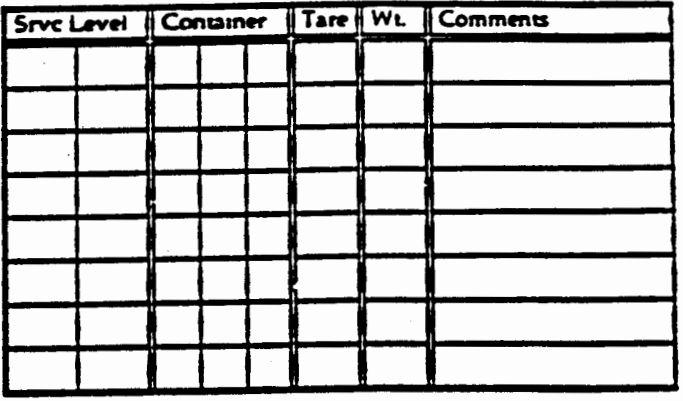

Srve Lred Contaner Tare / Wh Commens

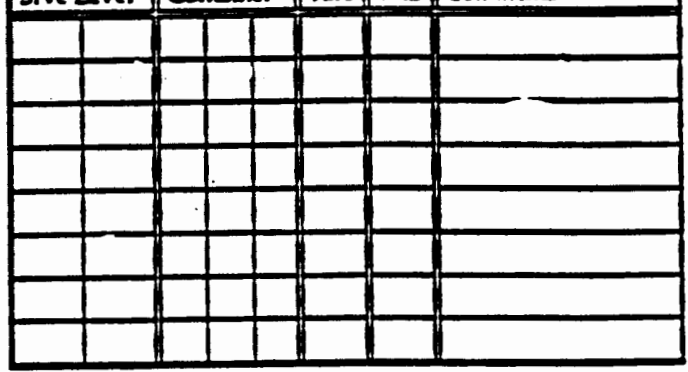

Address:

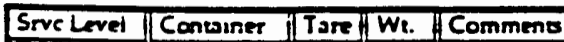

\begin{tabular}{|l|l|l|l|l|l|l|l|}
\hline \multicolumn{2}{|l|}{ Sive Level } & \multicolumn{2}{|l|}{ Conwiser } & Tare & W. & Commens \\
\hline & & & & & & & \\
\hline & & & & & & & \\
\hline & & & & & & & \\
\hline & & & & & & & \\
\hline & & & & & & & \\
\hline & & & & & & & \\
\hline & & & & & & \\
\hline
\end{tabular}

Srveleved [Conlasner Tarel We Comments

\begin{tabular}{|l|l|l|l|l|l|l|l|}
\hline & & & & & & & \\
\hline & & & & & & & \\
\hline & & & & & & & \\
\hline & & & & & & & \\
\hline & & & & & & & \\
\hline & & & & & & & \\
\hline & & & & & & & \\
\hline & & & & & & & \\
\hline
\end{tabular}





\section{Solid Waste Container Weight Project}

Field Observation Notes

Section:

$-$

Date:

Route: Garbage

Recycling

Yard Debris

Field Resesearchers Names:

Time Started:

Time Completed:

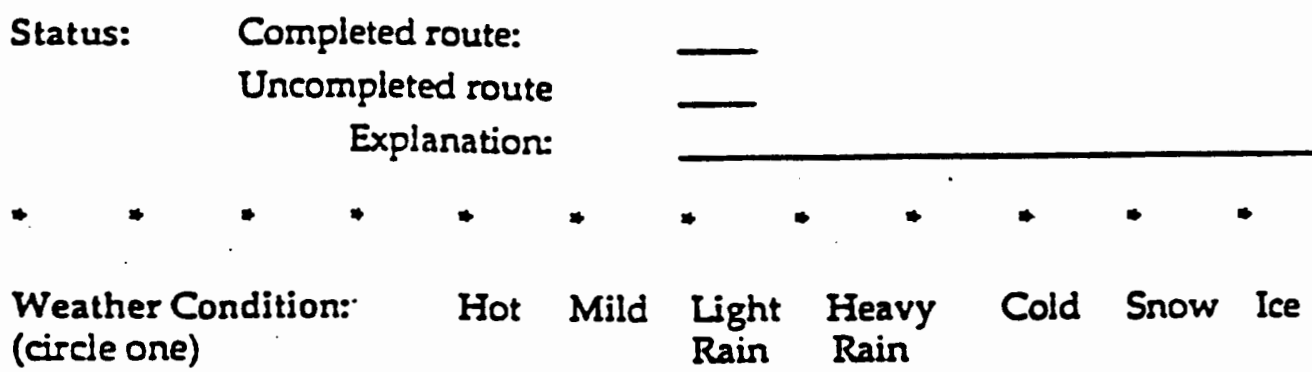

Neighborhood Observations (describe neighorhood characteristics):

Contact (describe any contacts with residents or other persons encountered on route):

Additional Notes: 


\section{APPENDIX F}

USES FOR MIXED-GRADE SCRAP PAPER

Sources: Apotheker 1990; Friberg 1993; Metro 1993b. 


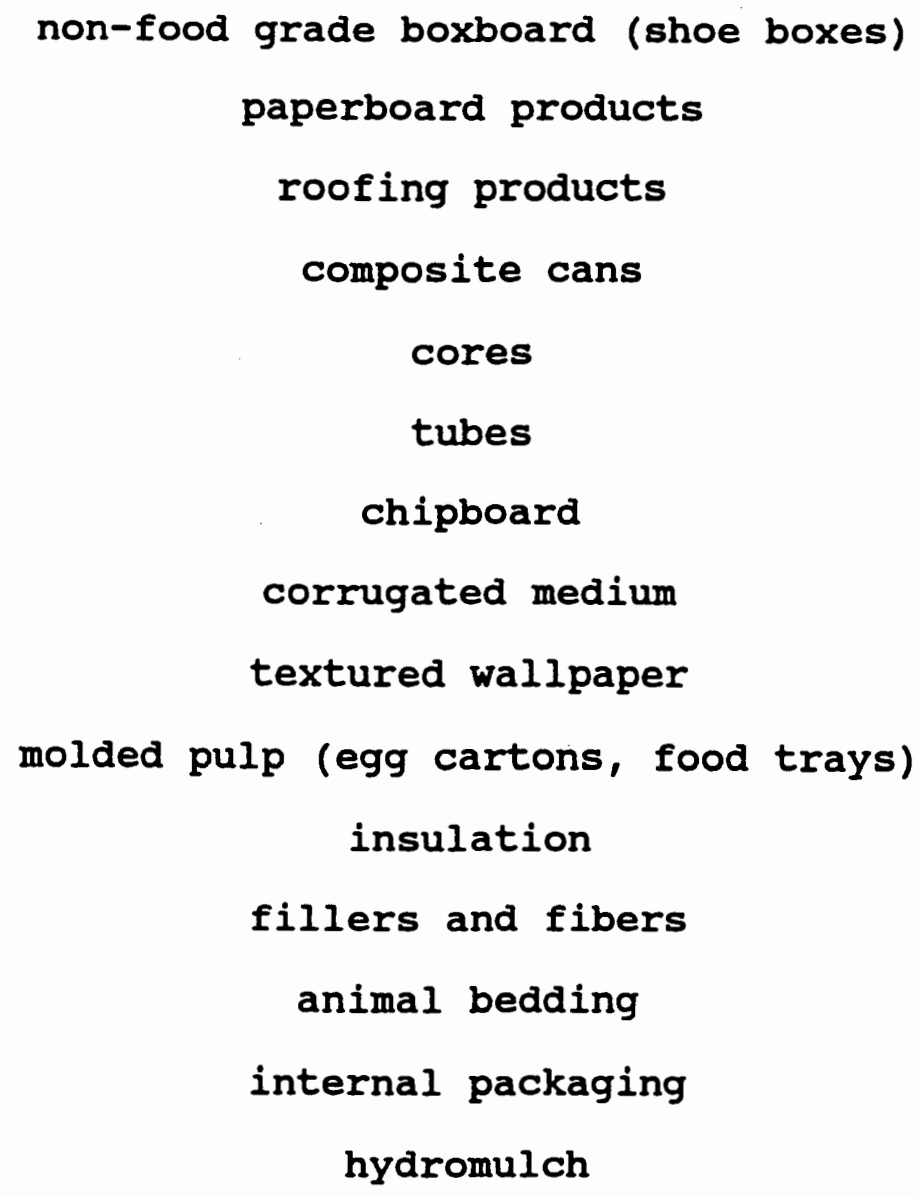




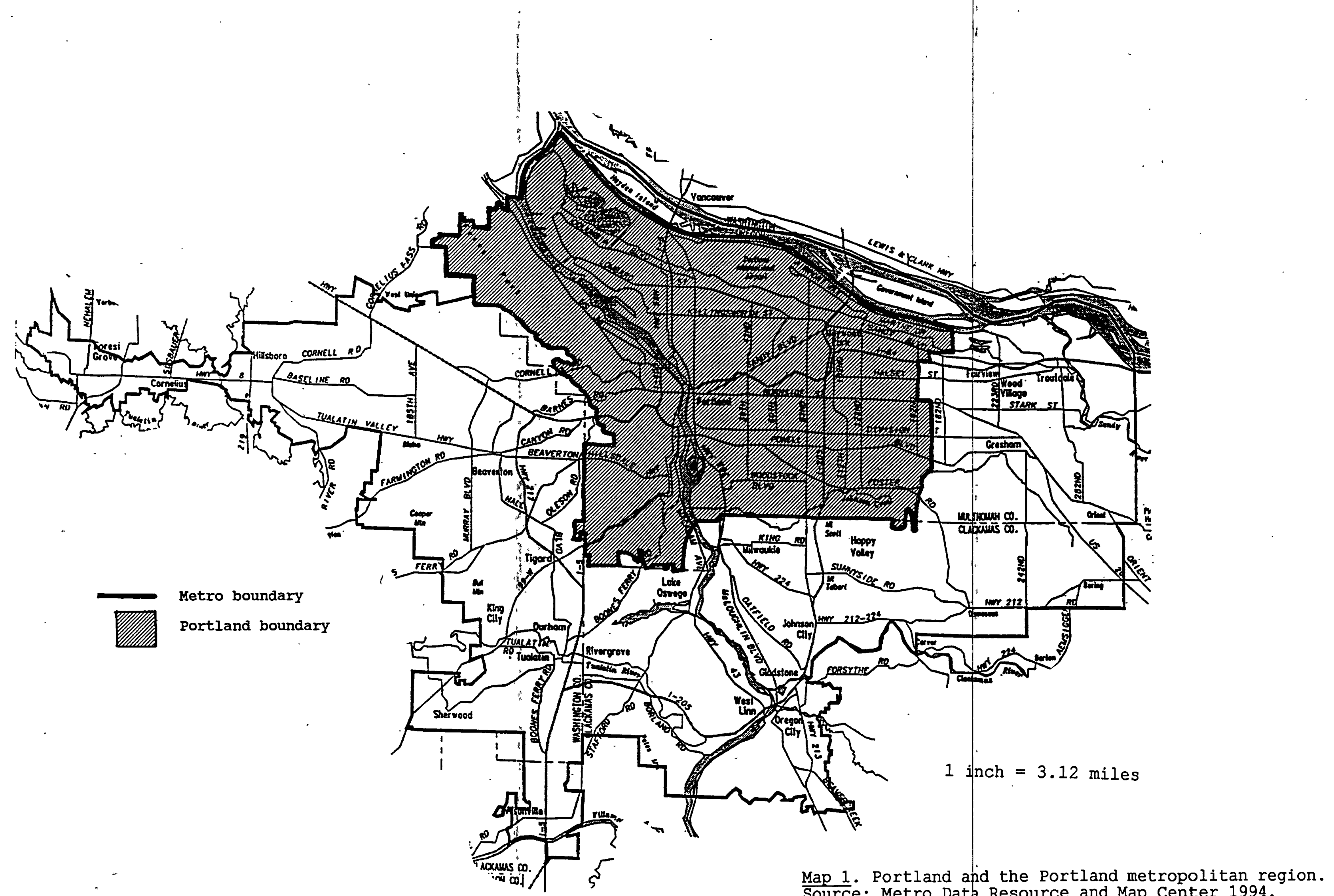

Map 1. Portland and the Portland metropolitan region.

An Analysis of Socioeconomic Effects on Scrap Paper Recycling Participation, Sara P. Zimmerman 



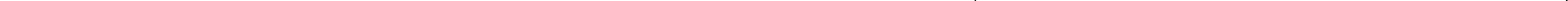




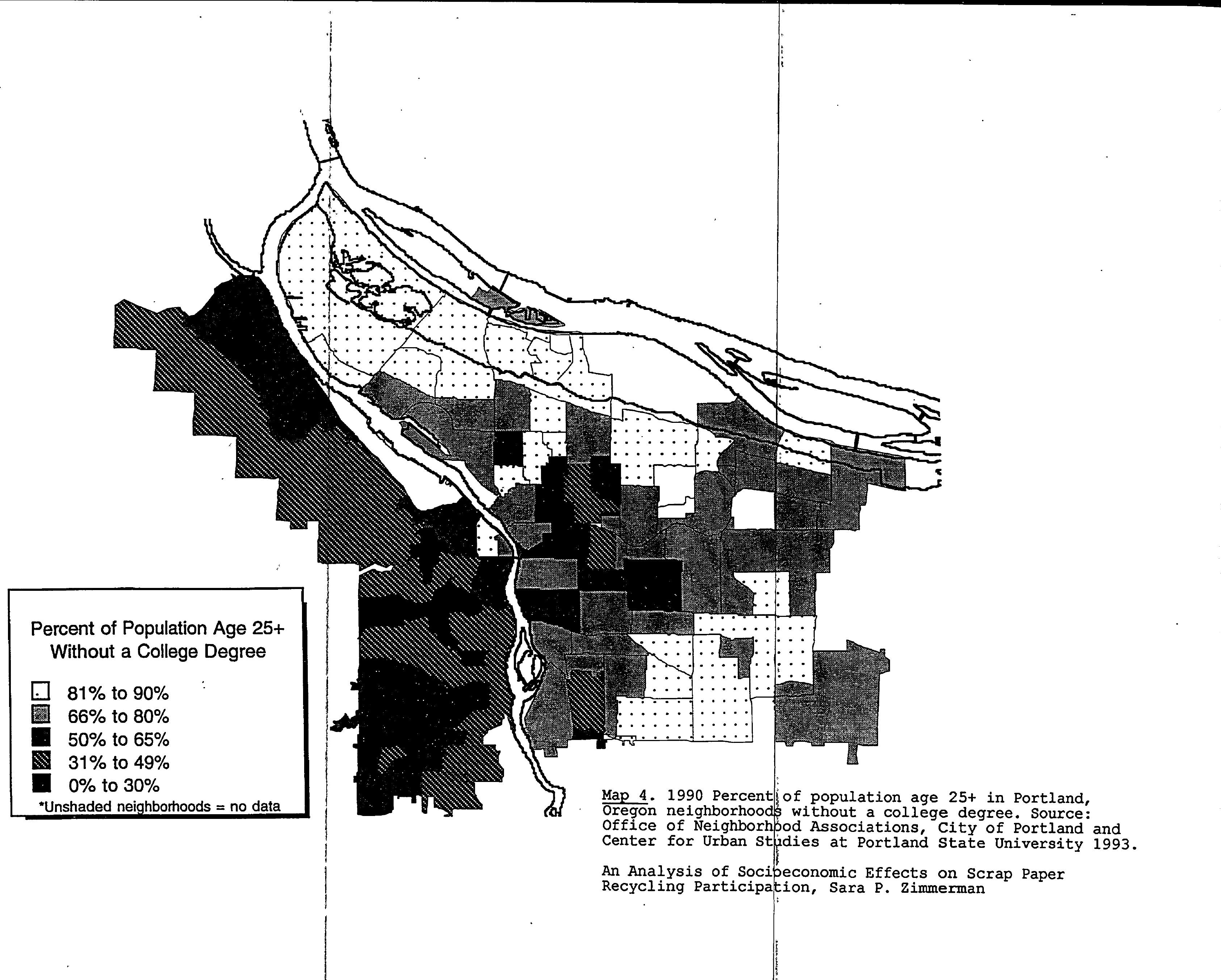




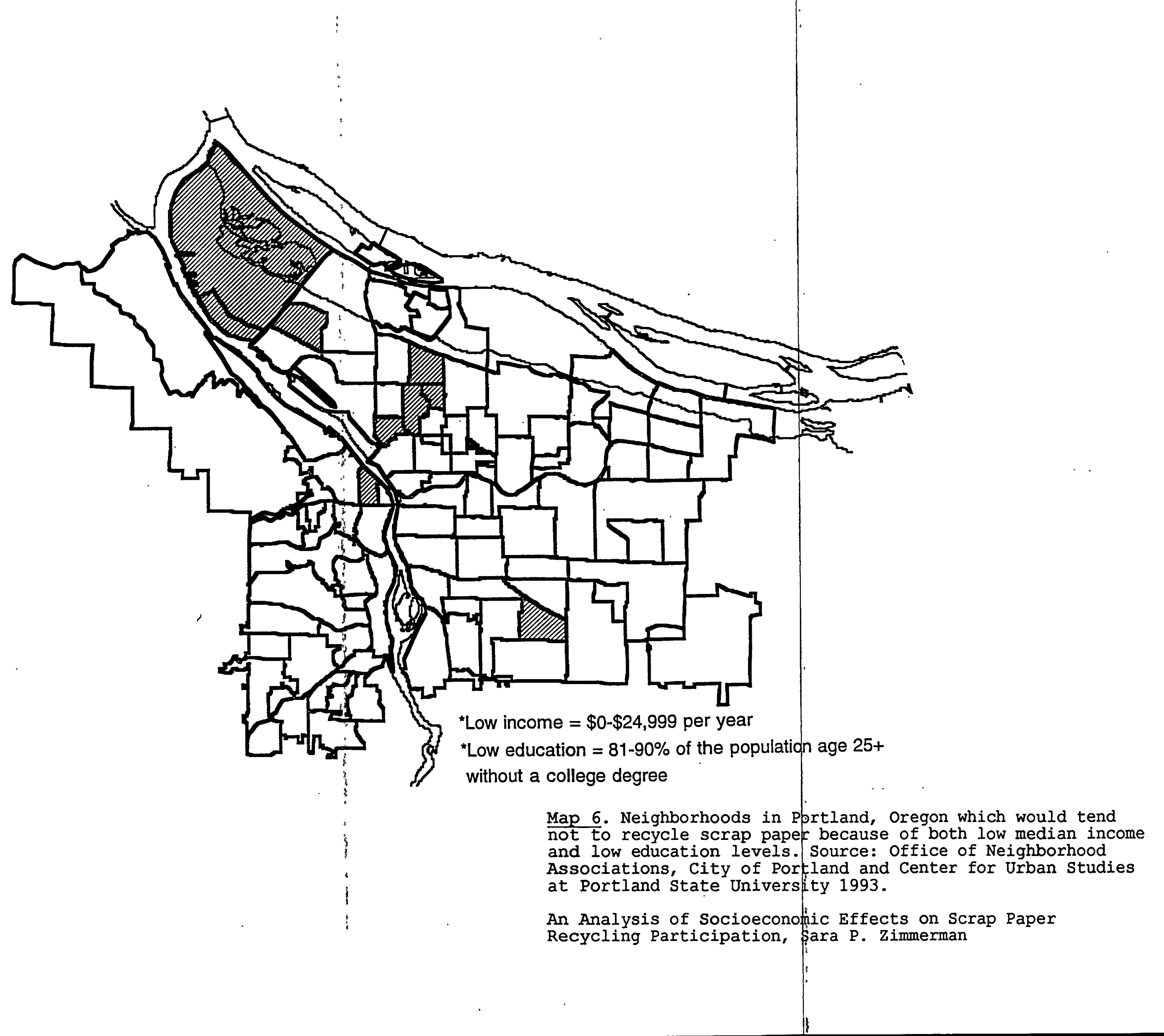

